
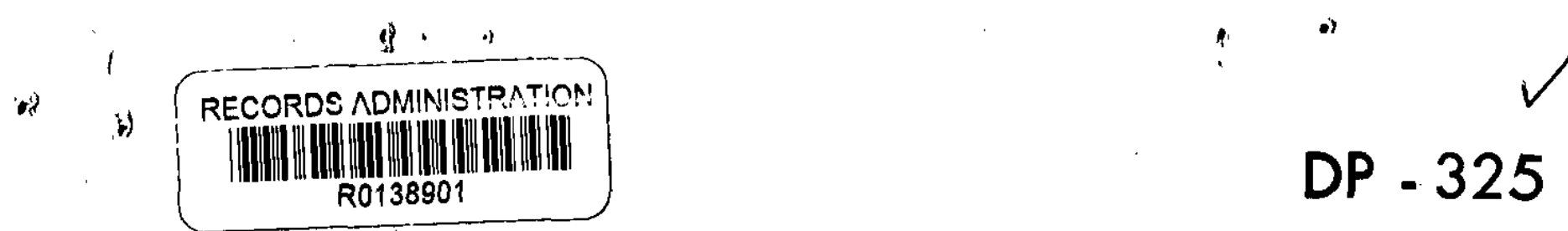

Reactors - General

AEC Research and Development Report
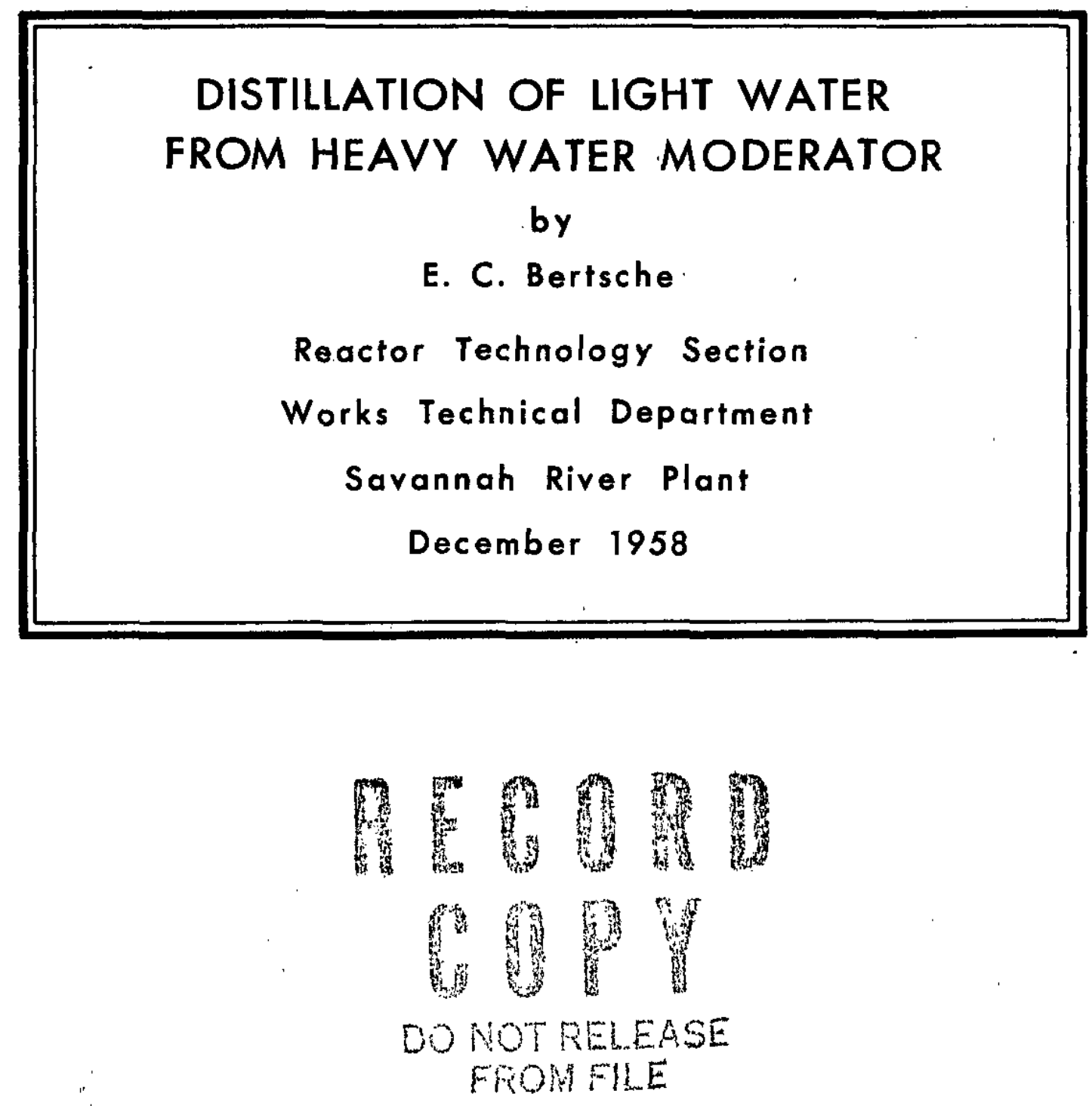

Issued by

E. I. du Pont de Nemours \& Co.

Explosives Department - Atomic Energy Division

Technical Division - Savannah River Laboratory 
This report was prepared as an account of Government sponsored work. Neither the United States, nor the Commlssion, nor any person acting on behalf of the Commission:

A. Makes any warranty or representation, express. or implied, with respect to the accuracy, completeness, or usefulness of the information contained in this report, or that the use of any information, apparatus, method, or process d1sclosed in this report may not infringe privately owned rights; or

B. Assumes any liabllities with respect to the use of , or for damages resulting from the use of any information, apparatus, method, or process disclosed in this report.

As used in the above, "person acting on behalf of the Commission" Includes any employee or contractor of the Commission to the extent that such employee or contractor prepares, handles or distributes, or provides access to, any information pursuant to his employment or contract with the Commission.

Printed in USA. Price $\$ 1.75$

Avallable from the office of Technical Services

U. S. Department of Commerce

Washington 25, D. C. 
REACTORS - GENERAL

(TID-4500, 14th Ed.)

\title{
DISTILLATION OF LIGHT WATER
} FROM HEAVY WATER MODERATOR

\author{
by \\ Edwin C. Bertsche \\ Reactor Technology Section \\ Works Technical Department \\ Savannah River Plant
}

December 1958

\section{Issued by}

E. I. du Pont de Nemours \& Co.

Explosives Department - Atomic Energy Division

Technical Division - Savannah River Laboratory

\section{Printed for}

The United States Atomic Energy Commission

Contract $\operatorname{AT}(07-2)-1$ 


\section{ABSTRACT}

A description is given of the equipment and method of operation of a distillation system to remove light water from heavy water moderator. The basic principles of the theory of distillation are reviewed. 


\section{CONTENTS}

$\underline{\text { Page }}$

LIST OF FIGURES

INTRODUCTION

PROCESS

THEORY AND DESIGN 6

General D1stillation Theory 6

The $\mathrm{H}_{2} \mathrm{O}-\mathrm{D}_{2} \mathrm{O}$ System 8

The $\mathrm{H}_{2} \mathrm{O}-\mathrm{D}_{2} \mathrm{O}-\mathrm{T}_{2} \mathrm{O}$ System 9

Operating Pressure 10

Bollup 10

Concentration 11

Drawoff Rate 11

Optimum Drawoff Ratez 11

Primary Feed Rate 12

Secondary Feed 12

Efficiency Standards 13

Distillation System Efficiency 13

Light Water Removal Efficiency 14

Batch Distillation System Occupancy and Efficiency 15

Reconcentration Efficiency 16

Design Basis 16

$\begin{array}{ll}\text { EQUIPMENT } & 17\end{array}$

Materials of Construction $\quad 17$

Columns 18

Rebollers 19

Column Condensers 19

Reboiler Separator 19

Bottoms Cooler 20

Bottoms Filters 21

Rundown Tanks 21

Vacuum Pump System 22

Vent Drying System

Miscellaneous Pumps 24

Instrumentation $\quad 26$

OPERATION 28

Startup 29

Normal Distillation 29

Shutdown 30

Batch Distillation 30

Differences in the Two Types of Distillation Systems 31

Light Water and Air Inleakage 34

BIBIIOGRAPHY 


\section{LIST OF FIGURES}

F1gure

$\underline{\text { Page }}$

1 Dist1llation Flowsheet - (Type 1) 35

2 Distillation Flowsheet - (Type 2) 36

3 Equilibrium Concentrations of $\mathrm{H}_{2} \mathrm{O}, \mathrm{D}_{2} \mathrm{O}$, and $\mathrm{HDO}$ vs Over-all Concentration of $\mathrm{D}_{2} \mathrm{O}$ in Water 37

4 Simplified Relative Volatility Curve for $\mathrm{T}_{\mathbf{2}} \mathrm{O}$ in $\mathrm{D}_{2} \mathrm{O}-\mathrm{H}_{2} \mathrm{O}$ Mixtures

Relative Volatility of $\mathrm{H}_{2} \mathrm{O} / \mathrm{HDO}$ vs Vapor Pressure

6 Bollup Rate vs Pressure Drop

7 Drawoff Rate vs $\mathrm{H}_{2} \mathrm{O}$ Production and $\mathrm{B}$ Overheads Concentration

8 Batch Distillation Feed Capac1ty vs Feed Concentration

9 Secondary Feed Rate vs $\mathrm{H}_{2} \mathrm{O}$ Production Rate at Various Drawoff Rates

10 Drawoff Rate vs $\mathrm{H}_{2} \mathrm{O}$ Production Rate at Various Secondary Feed Rates

Light water Production and Elimination Rates vs Secondary Feed Concentration. 42

$12 \mathrm{H}_{2} \mathrm{O}$ Inventory vs $\mathrm{B}$ Overheads Concentration at Varlous Steam Flows and Drawoff Rates

Standard Iight Water Production Rate (No Secondary Feed)

14 Column

Reboller

$\begin{array}{lll}17 & \text { Column Condenser } & 48 \\ 18 & \text { Reboller Separator } & 49\end{array}$

19 Bottoms Cooler (Type 1) 50

20 Bottoms Cooler (Type 2) 51

21 Bottoms Filter 52

22 Rundown Tank 53

23. Vacuum Pump 53

24 Vacuum Pump Separator ... .. 54

25 Vacuum Pump Cooler. 55

26 Vent Condenser (Type 1) 56

27 Vent Gas Dryer (Type 2) 57

28 Metering Pump. 58

29 Centrifugal Pump Characterlstic Curves 58

30 Vacuum Pump Characterist1c Curves 59

31 Distillation System Concentrations 59

Plot for Determining Amount of Drawoff
to Change A Bottoms Concentration

Feed Concentration and B Overheads Concentration
at Various Drawoff Rates

34 Plot for Determining Amount of Drawoff
to Change B Overheads Concentration

35 Plot for Locating Secondary Feed Polnt 63 


\section{DISTILLATION OF LIGHT WATER \\ FROM HEAVY WATER MODERATOR}

\section{INTRODUCTION}

The 1sotopic purity of heavy water used as moderator in a reactor is an important factor in maintaining productivity and neutron efficiency. Each purification system for the five reactors at the Savannah River Plant (SRP) Is equipped with a distillation system designed to remove small amounts of light water which enter the reactor moderator. The distillation overheads product is richer in light water than the bottoms and is reconcentrated before being returned to the reactor, whlle the bottoms product is directly recycled to the reactor.

\section{PROCESS}

The moderator purification system removes light water by isotopic distillation, suspended materials by filtration, lonic impurities by Ion exchange, and gases by sweeping hellum over the surface of the moderator. A normal flow of $30 \mathrm{gpm}$ of heavy water is pumped through the filters and delonizers.

Most of the moderator is returned to the main circulation stream. However, a $7-\mathrm{gpm}$ sidestream is sent to the distillation system where it is continuously distilled in two series-connected 90-sieve-plate columns operated under vacuum. The system has a rectifying section* in which the concentration of llght water in the feed moderator (typically $0.25 \mathrm{~mol} \% \mathrm{H}_{2} \mathrm{O}$ ) is increased to about $12 \mathrm{~mol} \% \mathrm{H}_{2} \mathrm{O}$ (the overheads composition), and a stripping section** in which it is decreased to about $0.23 \mathrm{~mol} \% \mathrm{H}_{2} \mathrm{O}$ (the bottoms composition).

The design capacity of the stills for a single feed to the bottom plate $1 \mathrm{~s} 1150$ to 1250 pounds of $\mathrm{H}_{2} \mathrm{O}$ per year at a feed composition of $99.75 \mathrm{~mol} \% \mathrm{D}_{2} \mathrm{O}$ (reactor moderator purity), an overheads drawof of 1.5 pounds per hour, a vacuum of $100 \mathrm{~mm} \mathrm{Hg}$ absolute at the condensers, and a bollup or reflux rate between 3000 and 4000 pounds per hour.

* The portion of a distillation column used to increase the concentration of the more volatile component (the $\mathrm{H}_{2} \mathrm{O}$ ) above the feed concentration is called the rectifying section.

* The portion of a distillation column used to increase the concentration of the less volatile component (the $D_{2} O$ ) above the feed concentration is called the stripping section. A complete fractionating column includes both a rectifying section above the feed plate and a stripping section below the feed plate. 
The distillation system is also used for batch distillation to reduce the heavy water and tritium oxide concentrations of the normal distillation overheads to a level which w1ll increase the heavy water reconcentration capacity of the reconcentration faclilties in the heavy water production area.

\section{THEORY AND DESIGN}

Methods of designing continuous distillation stills are described in deta1l in the various textbooks and handbooks of chemical engineering. The major considerations are reviewed briefly in this section.

\section{GENERAL DISTILLATION THEORY}

The vapor above a liquid mixture of two chemlcals w1ll normally be richer in one chemlcal (the one having a higher vapor pressure) than is the 11quid. The rat1o of $y$ (the concentration of the more volatile component in the vapor over a liquid mixture) to $x$ (1ts concentration in the liquid) is defined as the relative volatility ( $\alpha$ ) of the component according to the following formula:

$$
\alpha=\frac{y /(1-y)}{x /(1-x)}
$$

Relative volatility is independent of concentration for materials which follow Raoult's law* closely, but does vary with pressure and temperature.

A single partial evaporation of a liquid and the subsequent condensation of this vapor will therefore produce a condensate which has a higher concentration of the more volatile component. A further increase can be obtained by partial re-evaporation of the condensate, and condensation of this second vapor. A distillation column is a plece of equipment in which a large number of these partial evaporation-condensation stages can be carried out sequentially. If a sufficlent number of plates are used, the overheads product will contain only a small amount of materlal other than the more volatile component, while the bottoms product w1ll contaln practically none of the more volatile component.**

* Raoult's law states that the partial pressure of any component should equal the vapor pressure of that component in the pure state times $1 \mathrm{ts}$ mol fraction in the liquid. The behavior of many materials does not deviate widely from Raoult's law.

* Providing the vapor pressure of each component does not deviate widely from Raoult's law. 
The number of theoretical plates required for a given separation (1e, the number of plates that would be required if the vapor and Iiquid on each plate were in complete equilibrium) can be determined from the relative volatility and the desired equilibrium overheads and bottoms concentrations.* The actual number of plates required is higher than the theoretical number since complete equilibrium is never attained in practice. The ratio of the actual increase in concentration to the theoretically attainable increase in concentration of the more volatile component is defined as the distillation efficiency. This efficlency is affected by liquid and gas velocities, type of packing or plate, column design, and concentration gradients in the liquid phase.

A number of different types of efficlency factors have been proposed, but the two most commonly used are the over-all column efficiency which was proposed by Lewis, and the plate or point efficiency factors suggested by Murphree. The over-all column efficlency, $\mathrm{E}^{\circ}$, is the number of theoretical plates necessary for a given separation divided by the number of actual plates required to perform the same separation. This over-all column efficlency has no fundamental mass transfer basis, but it serves as an easily applied and valuable design factor and is therefore widely used. In the SRP systems, IBM calculations indicate that there are about 110 theoretical plates, or an over-all column efflctency of about $62 \%$, In the two columns.

The I hurphree efficlencles are based on more fundamental concepts than the over-all column efflciency but are harder to determine. The basic relationships employed are more qualitative than quantitative. They are based on calculations of point efficiencies over the entire

* The number of theoretical plates required to attain a desired enrichment at total reflux may be calculated from the following formula:

$$
\text { Enrichment }=\alpha^{P}
$$

where $\alpha$ is the relative volatility at each plate, and

$P$ is the number of theoretical plates in the column.

If the relative volatility is assumed to be constant throughout the column (ie, if the pressure drop through the column is assumed to be zero) and to be equal to the average value in the column $\left(a_{\text {avg }}\right)$, the actual number of plates needed for a given enrichment may be calculated from the following formula:

$$
\text { Enrichment }=\alpha_{\text {avg }} \mathrm{pE}
$$

where $E$ is the average plate efficiency, and $\mathrm{p}$ is the number of actual plates. 
plate for each plate in a still on the assumption that the I1quid at a point is of constant composition while the vapor composition in a bubble rising through the liquid on that plate changes continuously due to mass transfer.

The enrichment factor attained in a distiliation column is a function of the ratio of the concentration of the more volatile component in the column overheads $\left(\mathrm{y}_{\mathrm{T}}\right)$ to the concentration of that component in the column bottoms $\left(\mathrm{y}_{\mathrm{B}}\right)$ and is expressed by the following equation:

$$
\text { Enrichment Factor }=\frac{\frac{y_{T}}{1-y_{T}}}{\frac{y_{B}}{1-y_{B}}}
$$

Similarly, the attenuation factor attained in a distiliation column is defined as the ratio of the concentration of the less volatile component in the column bottoms $\left(x_{B}\right)$ to the concentration of that component in the column overheads $\left(x_{\mathrm{T}}\right)$ :

$$
\text { Attenuation Factor }=\frac{x_{B}}{x_{T}}
$$

Each column will finally attain an enrichment of 10 at equilibrium at total reflux after belng operated for about 150 hours. However, when the system is operated at 1.5 pounds per hour drawoff, the normal enrichment in the A column of 5.1 and in the B column of 9.7 w1II be attalned in about 78 hours. Thus, a distillation system can be put into normal operation 78 hours after inftial startup, provided the average composition of the moderator charge 1s equivalent to the desired steady state A bottoms and B overheads concentration (as is the case when the system is shut down and started up w1thout adding or removing moderator).

\section{THE $\mathrm{H}_{2} \mathrm{O} \cdot \mathrm{D}_{2} \mathrm{O}$ SYSTEM}

Water which contains both hydrogen and deuterium contains three compounds, $\mathrm{H}_{2} \mathrm{O}, \mathrm{HDO}$, and $\mathrm{D}_{2} \mathrm{O}$, existing together in equilibrium concentration. The equilibrium is established rapldiy, so that for practical purposes all such mixtures can be considered at equilibrium. A chart of equilibrium composition vs concentration of deuterium in 
water is shown in Figure 3. This chart shows that at low concentrations of deuterium most of the water $1 \mathrm{~s} \mathrm{H}_{2} \mathrm{O}$ and HDO and very little is $\mathrm{D}_{2} \mathrm{O}$, and that at high concentrations of deuterium most of the water is $\mathrm{D}_{2} \mathrm{O}$ and $\mathrm{HDO}$ and very little is $\mathrm{H}_{2} \mathrm{O}$.* Only near the middle of the range are $\mathrm{H}_{2} \mathrm{O}, \mathrm{HDO}$, and $\mathrm{D}_{2} \mathrm{O}$ all present in appreciable amounts.

For low concentrations of $\mathrm{D}_{2} \mathrm{O}$ the effective separation factor for distillation is the relative volatility of $\mathrm{H}_{2} \mathrm{O}$ and $\mathrm{HDO}$, while for high concentrations of $\mathrm{D}_{2} \mathrm{O}$ the effective separation factor is the relative volatility for $\mathrm{HDO}$ and $\mathrm{D}_{2} \mathrm{O}$.

The relative volatility for $\mathrm{HDO}-\mathrm{D}_{2} \mathrm{O}$, which is numerically the same as that for $\mathrm{H}_{2} \mathrm{O}-\mathrm{HDO}$, was used in the design calculations over the entire range of concentrations. This assumption of a simple two-component system disregarded the fact that near the midpoint of the concentration range three components $\left(\mathrm{H}_{2} \mathrm{O}, \mathrm{HDO}\right.$, and $\left.\mathrm{D}_{2} \mathrm{O}\right)$ are actually present in appreciable amounts, and thus caused the design to be slightly conservative (the difference is not of practical significance). In making calculations for the assumed two-component systems, the entire deuterium content was expressed as mol $\% \mathrm{D}_{2} \mathrm{O}$ and the entire hydrogen content as mol $\% \mathrm{H}_{2} \mathrm{O}$. All concentrations in this report are so expressed for convenience.

\section{THE $\mathrm{H}_{2} \mathrm{O}-\mathrm{D}_{2} \mathrm{O}-\mathrm{T}_{2} \mathrm{O}$ SYSTEM}

During reactor operation, tritium, the very heavy isotope of hyorogen, is produced in the moderator and is present as tritium oxide or very heavy water. Thus an equilibrium mixture of moderator contains $\mathrm{T}_{2} \mathrm{O}$, $\mathrm{HTO}$, and DTO in addition to the $\mathrm{H}_{2} \mathrm{O}, \mathrm{D}_{2} \mathrm{O}$, and $\mathrm{HDO}$. No reliable vapor pressure data for tritium oxide were avaliable during the design of the distillation columns. The design was therefore based on the assumption that the ratio of the vapor pressure of tritium oxide $\left(\mathrm{T}_{2} \mathrm{O}\right)$ to that of deuterium oxide $\left(\mathrm{D}_{2} \mathrm{O}\right)$ was the same as that for deuterium oxide $\left(\mathrm{D}_{2} \mathrm{O}\right)$ to light water $\left(\mathrm{H}_{2} \mathrm{O}\right)$. From these figures the design tritium attenuation factor was calculated to be between 50 and 100 .

However, unpublished data recelved from Los Alamos in 1954 indicated that the vapor pressure of tritium oxide is only slightly lower than that of heavy water. From this it appeared that the tritium attenuation factor in a reactor distillation system should be between 2 and 5. The actual attenuation factors experienced during operation of the stills at SRP were 3.0 at total reflux, 2.86 at $1.5 \mathrm{lb} / \mathrm{hr}$ drawoff, and 2.5 at $4.0 \mathrm{lb} / \mathrm{hr}$ drawoff. The average relative volatility

* The moderator normally found in the reactor system and the distillation system is high in $\mathrm{D}_{2} \mathrm{O}$ content (80 to $100 \mathrm{~mol} \%$ ) and is predominantly $\mathrm{D}_{2} \mathrm{O}$ and $\mathrm{HDO}$. 
calculated from these attenuation factors was found to be in close agreement with the Los Alamos data and is shown in Figure 4 as a simplifled tritium vapor pressure curve of relative volatility vs mol \$ $\mathrm{D}_{2} \mathrm{O}$. This graph assumes that the tritium is present only as HTO or DTO and not as $\mathrm{T}_{2} \mathrm{O}$. It also neglects the effect of HDO on the HTO and DTO vapor pressures, since this effect would be small.

\section{OPERATING PRESSURE}

The relative volatility varles significantly with temperature, and consequently (since the moderator in the column is bolling) with the pressure prevalling in the distillation equipment. The lower the pressure at which the distillation process is operated, the lower is the temperature and the greater is the relative volatility (and consequently the greater the separation). A plot of the relative volatility of $\mathrm{H}_{2} \mathrm{O}-\mathrm{HDO}$ vs pressure of the bolling mixture is shown in Figure 5 .

The volume of the vapor generated by bolling increases as the pressure decreases, and this increases the velocity of the gas ascending the column. At a constant bollup rate, therefore, when the pressure has been sufficlently decreased, the gas velocity will become high enough to cause the liquid in the column to entrain into the gas phase and into the liquid on the next higher plate; this will decrease the column efficlency. Finally, as the gas velocity increases still further, all the liquid will be entrained with the vapor, and the column wlll no longer separate the high and low vapor pressure components.

The optimum operating pressure for a still was selected by balancing the effect of pressure on both relative volatility and entrainment. In the $\mathrm{H}_{2} \mathrm{O}-\mathrm{D}_{2} \mathrm{O}-\mathrm{T}_{2} \mathrm{O}$ system, the optimum vapor pressure on the basis of theoretical considerations (conflrmed by operating experience) is about $100 \mathrm{~mm} \mathrm{Hg}$ absolute.

\section{BOILUP}

The theoretical capacity of a distillation column is a function of several factors. It is directly proportional to the product of the boilup rate and the relative volatility minus 1 (ie, $\alpha-1$ ) and thus for most systems w1ll increase as the bollup is increased. However, as the bollup is increased at a constant pressure, the gas velocity and the pressure drop increase (as shown in Figure 6), and eventually will cause sufficient liquid entrainment to decrease the column efficiency. The optimum boliup rate, therefore, has to be chosen on the basis of: (1) the increase in capacity resulting from the higher bollup, (2) the decrease in capacity caused by entrainment, and (3) the decrease in average relative volatility caused by the higher average pressure in the column (see "Operating Pressure" above). 


\section{CONCENTRATION}

The light water concentration of the feed to a distillation system has a direct effect on the light water production capacity. Since the enrichment factor in a column does not change if all other operating variables are kept constant, the overheads concentration is equal to the product of the bottoms concentration and the enrichment.* Thus at an enrichment factor of 48 , a drawoff rate of $1.5 \mathrm{lb} / \mathrm{hr}$, and a bottoms concentration of $0.50 \mathrm{~mol} \% \mathrm{H}_{2} \mathrm{O}\left(99.50 \mathrm{~mol} \% \mathrm{D}_{2} \mathrm{O}\right)$, the overheads concentration will be $20 \mathrm{~mol}$ of $\mathrm{H}_{2} \mathrm{O}\left(80 \mathrm{~mol} \% \mathrm{D}_{2} \mathrm{O}\right.$ or 18.37 wt $\%$ $\mathrm{H}_{2} \mathrm{O}$ ), and the production rate will be 0.28 pound of $\mathrm{H}_{2} \mathrm{O}$ per hour or 6.7 pounds per day. If the feed concentration is 99.75 mol to $D_{2} \mathrm{O}$ at the same drawoff rate and enrichment factor, the overheads concentration will decrease to $10 \mathrm{~mol} \% \mathrm{H}_{2} \mathrm{O}$ (90 mol $\% \mathrm{D}_{2} \mathrm{O}$ or 9.1 wt $\% \mathrm{H}_{2} \mathrm{O}$ ), and the production rate will decrease to 0.14 pound per hour or 3.35 pounds per day.

\section{DRAWOFF RATE}

The rate of removal of overheads product from the $B$ column influences both the concentration gradient of light water throughout the stills and the rate of production of light water. As can be seen from Figure 7 , the rate of production of light water increases as the drawoff rate increases.** However, as the drawoff rate becomes large, the increase in production rate per unit increase in drawoff rate grows smaller and becomes negligible at drawoff rates over about $15 \mathrm{lb} / \mathrm{hr}$. The heavy water concentration of the $\mathrm{B}$ overheads product increases similarly, finally asymptotically approaching the feed concentration as a maximum value.

\section{OPTIMUM DRAWOFF RATES}

The maximum rate for continuously removing light water from the reactor moderator is achleved when the total overheads drawoff from the normal distillation systems (after processing through a batch distillation system) is just equivalent to the tritium blending capacity in the heavy water production area. The total amount of moderator which has to be processed in the batch distillation system each month to attain this maximum rate is defined as the "Batch Distillation Feed Capacity" (BFC) and is determined from Figure 8 (using the average concentration of heavy water in the overheads from the normal stills). The drawoff rate for each normal still is then calculated from the formula shown on the following page.

* According to the formula $\mathrm{y}_{\mathrm{T}} /\left(1-\mathrm{y}_{\mathrm{T}}\right)=\mathrm{Ey}_{\mathrm{B}} /\left(1-\mathrm{y}_{\mathrm{B}}\right)$.

* For a distillation system operating with a single primary feed. 


$$
\frac{B F C}{672}=T_{1} D_{1}+T_{2} D_{2}+T_{3} D_{3}+T_{4} D_{4}+T_{5} D_{5}+P
$$

$$
\begin{aligned}
\text { where } \mathrm{BFC}= & \text { batch distillation feed capac1ty } \\
672= & \text { hours per month (allowing } 2 \text { days per month outage) } \\
\mathrm{T}= & \text { tritium content In normal still overheads } \\
\mathrm{D}= & \text { drawoff rate, } 1 \mathrm{~b} / \mathrm{hr} \\
\mathrm{I}, 2,3,4,5= & \text { areas operating as normal distillation systems* } \\
\mathrm{P}= & \text { tritium content of other degraded moderator } \\
& \text { (not overheads) whtch has been produced by leaks, } \\
& \text { splils, etc. }
\end{aligned}
$$

The drawoff rate should not exceed $14 \mathrm{Ib} / \mathrm{hr}$ even if the tritium processing capacity in the heavy water production area were to become infinite, since at that rate the optimum balance between production increase and reworking costs in the distillation system is achieved.

\section{PRIMARY FEED RATE}

The rate at which moderator is pumped into the distillation column is about $7 \mathrm{gpm}$ in all areas. As long as the feed composition, the bollup rate, and the drawoff rate are maintained constant, the production capacity of the still will increase less than $3 \%$ if the feed rate is raised by $200 \%$ (from 5 to $15 \mathrm{gpm}$ ). In two reactor areas (Type 1 Areas) the feed rate was arbitrarliy set at $7 \mathrm{gpm}$ since the resultant hourly turnover of bottoms liquid assures an adequate purge of contaminants. The feed rate in the other three reactor areas (Type 2 Areas) is equal to the bollup rate, which is about $5 \mathrm{gpm}$.

\section{SECONDARY FEED}

The use of a secondary feed in addition to the normal primary feed increases the over-all light water production rate from the dist1llation system but decreases the rate of light water elimination from the reactor. As shown in Figures 9 and 10, the total light water production rate will be decreased if the secondary feed rate is increased without simultaneously increasing the drawoff rate. The quantitative relationship between secondary feed concentration and the rates of total light water production and of light water elimination from the reactor is shown in Figure 1l, at several secondary feed rates.** Increasing the secondary feed and drawoff

* When one area is operated as batch distillation system, only four areas are considered. This formula assumes that the batch distillation system is operating the entire month; thus it does not correct for the time the batch distillation system is shut down (during which time the batch distillation system could theoretically be used for normal distillation).

* The assumptions made in Figure 11 were: the drawof $f$ rate and secondary feed rate were equal; the primary feed concentration was $99.60 \mathrm{~mol}$ of $\mathrm{D}_{2} \mathrm{O}$; and the primary feed rate was $7.0 \mathrm{gpm}$. 
rates at any secondary feed concentration will not change the rate of elimination of light water from the reactor but will increase the total Iight water production rate. Decreasing the $\mathrm{D}_{2} \mathrm{O}$ concentration of the secondary feed decreases the rate of light water elimination from the reactor and increases the total light water production rate.

The distiliation columns are not operated with a secondary feed for the following reasons:

1. The amount of light water in the distillation system increases if the secondary feed rate is increased or if the light water concentration of the secondary feed is increased. Thus, if the distillation columns were to be shut down accidentally or to flood, considerably more dilution of reactor moderator would occur when operating with both secondary and primary feeds than when operating with just a primary feed.

2. The type of moderator which would be used for secondary feed frequently is contaminated with impurities which cannot be tolerated in the reactor system.

3. The secondary feed material can be upgraded more safely to reactor quality by operating one distillation system as a batch distiliation system. The possibility of contaminating or diluting the reactor system is completely avolded since during distiliation the system is isolated from the reactor system.

4. The loss of light water elimination capacity is about 6\% greater with secondary feed than by reconcentration in a batch distillation system.

\section{EFFICIENCY STANDARDS}

The highest rate of light water elimination from the reactor moderator occurs when the distillation equipment in the reactor areas and the rework capacity in the heavy water production area are both used at maximum efficiency. The effectiveness of these facilities can be evaluated by determining the following efficlency factors:

1. DISTILIATION SYSTEM EFFICIENCY

The efficiency of the distillation system in each area ( $F_{\text {still }}$ ) is a function of the amount of light water actualiy produced and the amount that could have been produced at the prescribed drawoff rate. The amount actually produced $\left(\mathrm{H}_{2} \mathrm{O}\right.$ act $)$ in a month is determined from records of the amount and analysis of the overheads product from a still. This figure is then corrected by use of Figure 12 for changes in the light water inventory ( $\Delta$ inventory) in the distillation columns caused by changes in 
moderator concentration during the month. The standard monthly ilght water production rate $\left(\mathrm{H}_{2} \mathrm{O} s t d\right)$ is determined from Figure 13 using the actual system purity and the optimum drawoff rate (described on page 11).

$$
\text { Thus* } \mathrm{F}_{\mathrm{st1} 11}=\frac{\mathrm{H}_{2} \mathrm{O}_{\text {act }}-\Delta \text { inventory }}{\mathrm{H}_{2} \mathrm{O}_{\mathrm{std}}}
$$

where $\mathrm{H}_{2} \mathrm{O}_{\text {act, }} \Delta$ inventory, and $\mathrm{H}_{2} \mathrm{O}_{\text {std }}$ are in $\mathrm{Ib} / \mathrm{mo}$.

\section{LIGHT WATER REMOVAL EFFICIENCY}

The efflciency of each system in removing light water from the moderator $\left(F_{\text {elim }}\right.$ ) is a function of the net amount of water actually removed from the reactor moderator and the amount $\left(\mathrm{H}_{2} \mathrm{O}_{\text {std }}\right)$ that could have been removed at the optimum drawoff rate.

The monthly net amount of water removed from the reactor is the amount actually removed during the month by the distillation columns ( $\mathrm{H}_{\mathbf{2}} \mathrm{O}_{\text {act }}-\Delta$ inventory), corrected for the light water content of the moderator added to the reactor during the month $\left(\mathrm{H}_{2} \mathrm{O}_{\text {makeup }}\right)$ as determined from the records.

Degraded moderator (purity below $99.0 \mathrm{~mol}$ \% $\mathrm{D}_{2} \mathrm{O}$ ) produced as a result of leaks, spills, equipment flushing, etc, has a very high tritium content and normally requires distillation before reconcentration in the heavy water production area. The batch distillation capacity for processing distillation overheads is thereby decreased, and the distillation overheads production rate must be decreased by an amount equal to the weight of degraded moderator produced. The resultant loss in light water removal capacity is equal to the quantity of light water that would be contalned in an amount of distillation overheads of the same weight as the monthly degraded moderator production.** This factor $\left(\mathrm{H}_{2} \mathrm{O}_{\text {degr }}\right.$ ) is calculated by multiplying the total weight of degraded moderator produced in the area during the month (from the records) by the average light water concentration of the distillation overheads product.

* See footnote * on page 15 for comment on the effect of secondary feed.

* Actually, the amount of light water removal capacity lost will be slightly less, since the time for reconcentration of moderator containing 95 to $98 \mathrm{~mol} \% \mathrm{D}_{2} \mathrm{O}$ will be somewhat shorter than the time for normal still overheads (85 to $90 \mathrm{~mol}$ \% $\left.\mathrm{D}_{2} \mathrm{O}\right)$. 


$$
\text { Thus* F } \mathrm{Fllm}_{\mathrm{m}}=\frac{\mathrm{H}_{2} \mathrm{O}_{\text {act }}-\Delta \text { inventory }-\mathrm{H}_{2} \mathrm{O}_{\text {makeup }}-\mathrm{H}_{2} \mathrm{O}_{\mathrm{degr}}}{\mathrm{H}_{2} \mathrm{O}_{\mathrm{Std}}}
$$

where $\mathrm{H}_{2} \mathrm{O}_{\text {act }}, \Delta$ inventory, $\mathrm{H}_{2} \mathrm{O}_{\text {makeup, }} \mathrm{H}_{2} \mathrm{O}_{\text {degr }}$, and $\mathrm{H}_{2} \mathrm{O}_{\text {std }}$ are in $1 \mathrm{~b} / \mathrm{mo}$.

\section{BATCH DISTILLATION SYSTEM OCCUPANCY AND EFFICIENCY}

The effectiveness of the batch distillation system depends both on the efficiency of separation of tritium from light water and on the time required to complete each batch distillation cycle. Two factors are therefore calculated: occupancy and separation efficiency.

\section{Occupancy}

This factor ( $F_{\text {Occ }}$ ), calculated for each batch distiliation system cycle, is the ratio of the standard cycle time of 12.0 days** to the actual cycle time in days $\left(t_{\text {actual }}\right)$. The actual cycle time starts when the first drum of moderator is added to the system and ends when the last drum is removed.

$$
\text { Thus } F_{\text {occ }}=\frac{12.0 \text { days }}{t_{\text {actual }}}
$$

\section{Separation Efficiency}

At total reflux the ability of the distillation system to concentrate tritium from the feed moderator into the bottoms product depends only on the plate and column efficiency of the equipment. This separation efficiency however is dependent both on the rate at whlch overheads product is removed during the slow drawoff period, and on the concentration at which slow drawoff is discontinued and fast drawoff started. Past experience has shown that when the distillation system is operated according to the standard procedure (described on page 30 of this report), the average concentration of tritium in the feed material (Tcharge) will be 4.5 times greater than the average tritium concentration

$\left(\mathrm{T}_{\mathrm{B} . \mathrm{D} . \mathrm{OH}}\right)$ of the overheads product removed during the slow drawoff period ( $u p$ to $48.0 \mathrm{~mol} \% \mathrm{D}_{2} \mathrm{O}$ ).

* As shown earlier in this report, the use of a secondary feed in addition to the normal primary feed increases the total overheads light water production rate, but decreases the ability of the stills to remove light water from the moderator. Thus, if a secondary feed is used both $F_{\text {stills }}$ and $F_{\text {elim }}$ require correction for the secondary feed before they are representative.

* This standard cycle time assumes operation according to the procedure described on page 30 of this report and is based on experience prior to May 1, 1956. 
The separation efflclency per cycle ( $\left.F_{B} . D.\right)$ can thus be determined from the following formula:

$$
\begin{gathered}
F(\mathrm{~B} . \mathrm{D} .)=\frac{\mathrm{T}_{\text {charge }}}{4.5 \times \mathrm{T}_{\mathrm{B} . \mathrm{D} \cdot \mathrm{OH}}} \\
\text { where } \mathrm{T}_{\text {charge }} \text { and } \mathrm{T}_{\mathrm{B} . \mathrm{D} . \mathrm{OH}} \text { are in } \mu \mathrm{c} / \mathrm{ml}
\end{gathered}
$$

\section{Reconcentration Efficiency}

The amount of degraded moderator that can be reconcentrated to an 1sotop1c purity of $99.75 \mathrm{~mol} \% \mathrm{D}_{2} \mathrm{O}$ depends on the maximum permissible tritium content of the heavy water product and the tritium actually contained in the degraded feed moderator. The monthly reconcentration efficiency can therefore be calculated from the following equation:

$$
\mathrm{F}_{\text {Rec. }}=\frac{\mathrm{T}_{\text {actual }}(1 \mathrm{~b} \times \mu \mathrm{c} / \mathrm{ml})}{350,000(1 \mathrm{~b} \times \mu \mathrm{c} / \mathrm{ml})}
$$

where $T_{\text {actual }}=$ the product of the welght of degraded moderator (Ib) sent for reprocessing in the heavy water production area in the month times the tritium content of this degraded moderator $(\mu \mathrm{c} / \mathrm{ml})$.

\section{DESIGN BASIS}

The distillation columns in each area were designed to remove about 1200 pounds of light water a year from the reactor moderator with a single feed stream to the bottom plate (primary feed). When an additional, more dilute stream (secondary feed) is added simultaneously to a higher plate in the column, the design capacity is 1000 pounds of light water from the primary feed and 1000 pounds of light water from the secondary feed. The actual light water production capacity of a distillation column operating with both a primary and a secondary feed depends on the drawoff rate and on the concentration and flow rate of each feed stream. This relationship is discussed earlier in this report in the sections on Drawoff Rate and Secondary Feed (pages 11 and 12 , respectively). 
The above capacity ratings were based on the use of two sieve plate columns ( 90 sleve plates each*) connected in series and operated at $100 \mathrm{~mm} \mathrm{Hg}$ absolute pressure, $3000 \mathrm{lb} / \mathrm{hr}$ bollup, $1.5 \mathrm{Ib} / \mathrm{hr}$ arawoff, $2998.5 \mathrm{lb} / \mathrm{hr}$ reflux (a reflux ratio of $2998.5 / 1.5$ or 1999.0 ), a primary feed (moderator) composition of 99.75 mol of $\mathrm{D}_{2} \mathrm{O}$, a secondary feed composition of $98.0 \mathrm{~mol}$ of $\mathrm{D}_{2} \mathrm{O}$, and an overheads concentration of $85 \mathrm{~mol}$ of $\mathrm{D}_{\mathbf{2}} \mathrm{O}$.

\section{EQUIPMENT}

The distiliation system consists of two sieve plate columns operated in series. Schematic process and flow diagrams for Type 1 Areas are presented in Figure 1 and for Type 2 Areas in Figure 2.

The major distillation equipment (columns, heat exchangers, pumps, tanks, and instruments) is described in detail in this section. Where equipment is of standard design (pumps, motors, instruments), only the functional specifications are presented. The equipment is identical in all areas except as noted.

\section{MATERIALS OF CONSTRUCTION}

Mild steel was used originally throughout all distillation systems, except for the stainless steel bottoms coolers in Type 2 Areas and the stainless steel bottoms filters in all areas. Stainless steel tubes and tube sheets were installed in the A column and B column condensers in all areas and in Type I bottoms coolers, after several of the orlginal mild steel units had falled due to corrosion from the cooling water side.

Stainless steel or other corrosion resistant material was not considered Justified, since only moderator which has previously been purified is added to the distillation equipment during normal distillation. The distillation feed moderator stream is taken from the purification effluent line and has been deionized and filtered through a 10-micron filter. In addition, this feed stream is continuously monitored for radiation, and the feed valve is automatically closed if the radiation level is slgniflcantly higher

* The design calculations initially assumed that two columns would be used, each having the same thermodynamic performance (the same light water enrichment ratio). On this basis, the first column required 103 actual plates and the second column 77 actual plates. When using a $99.75 \mathrm{~mol} \%$ primary feed, the first column had a concentration of $98.4 \mathrm{~mol} \% \mathrm{D}_{2} \mathrm{O}$ above the 90 th plate and $97.7 \mathrm{~mol}$ $\% \mathrm{D}_{2} \mathrm{O}$ above the 103rd or top plate. In the final design, the two columns were made identical (each using 90 actual plates) to decrease design and construction costs at only a slight loss in distillation efficiency. 
than background (the tritium present in the moderator produces a sof't beta radiation which is easily absorbed by the steel equipment or pipes). Th1s low radiation level permits the distillation system to be located in unshlelded areas inslde and outslde the bullding.

\section{COLUMNS}

The distillation columns (see Figure 14) are designed for temperatures up to $85^{\circ} \mathrm{C}$ and for pressures between full vacuum and $30 \mathrm{psig}$. After erection had been completed, a hydrostatic test at 65 psig (measured at the lowest point in the column) was performed as a fleld test for tightness. A pressure rellef valve is provided in the gas ine on each column to prevent the pressure on a column from exceeding 15 psig. Each distillation column is 82 feet $5-1 / 2$ inches high, we1ghs 32,830 pounds when lagged, and has a volumetric capacity of about 630 cublc feet. The column is supported by the 24-foot-high base section whose top 4 feet also contains the bottom head of the stili. The diameter of the upper section of the column proper is larger (47 inches in diameter for the 29-foot 9-1nch helght) than the lower section ( 41 inches in diameter for the 27-foot l-1nch helght) to compensate for the increase in vapor volume at the top of the column and to maintain the vapor velocity (which otherwise would have increased) within the desired limits. The bottom section contains 44 sleve plates: plates 1 through 35 at a 7 -inch spacing and plates 35 through 44 at an 8 -inch spacing. The top section contains 46 plates: plates 45 through 81 at a 7 -1nch spacing and plates 81 through 90 at an 8-inch spacing. Inlet feed connections are provided so that while the main feed is introduced to the reboller, an additional feed stream could be introduced to plates $2,10,30,50$, 70 , or 90 .

Al1 plates are perforated w1th $1 / 8$-1nch-dlameter holes on a 3/8-inch triangular pitch. All holes are punched downward so that the smooth slde of the plate is on top. As shown in Figure 15, the perforated area does not extend beyond a chord on elther slde of the plate. Three 2-Inch-dlameter downplpes are provided on one side to allow the liquid overflowing the weir to drain down to the next lower plate, and an empty space is provided on the other side to recelve the Ilquid from the next higher plate. The inlet welr ( $3 / 4$ inch high) serves to seal the downcomers from the higher plates and prevent gas from bypassing the sleve plates. On the outlet side, a baffle produces a quiet zone between the baffle and the outlet welr. The outlet weir thus can malntain a constant head of liquid on the plate, through which the vapor from the plate below bubbles in intimate contact with the I1quid. 


\section{REBOILERS}

The rebollers (see F1gure 16) are shell-and-tube heat exchangers with the moderator inside the tubes and the steam outside in the sheli. Steam is prevented from leaking into the moderator through the joints between the tubes and the tube sheets by the use of double tube sheets on each end of the exchanger. If a leak develops past the rolled inner tube sheet joint, steam wlll leak into the atmosphere. If a leak develops past the rolled and welded outer tube sheet jolnt, atmospheric air w11l leak into the distillation system, but this air will contain only a small amount of humidity.

Each reboller is 20 inches in diameter and contains 120 one-1nch-OD mild steel tubes (No. 14 BWG) on a 1-3/8-1nch triangular pitch. The tubes are 48 1nches long, but only the $31-1 / 8$ inches between the inner tube sheets is exposed to the steam and is useful for heat transfer. Thus the heat transfer area is 68 square feet for the design heat transfer capacity of $1.59 \times 10^{6} \mathrm{pcu} / \mathrm{hr}$. The calculated welght of an empty reboller is 1715 pounds, the tube side volume is about 7 cubic feet, and the shell side volume is about 3 cubic feet. The shell (steam) side $1 \mathrm{~s}$ deslgned for $50 \mathrm{ps} 1 \mathrm{~g}$ pressure at $150^{\circ} \mathrm{C}$, and the tube (process water) side is designed for full vacuum at $150^{\circ} \mathrm{C}$. The shell side is hydrostatically tested at 75 psig, while the tube side is given a 25-psig hydrostatic test f'ollowed by a 20-psig "Freon" test.

\section{COLUMN CONDENSERS}

The column condensers (see Figure 17) have the same baslc design as the reboliers, including the double tube sheets. Each condenser is 30 inches in diameter and contains 376 one-inch-OD tubes (No. 14 BWG) on a 1-3/8-inch trlangular pitch. The tubes are 8 feet long, but only the 7 feet 2-1/8 inches between the inner tube sheets is exposed to the cooling water and 1 s useful for heat transfer. Thus the heat transfer area 1 s 590 square feet for the design heat transfer capacity of $1.59 \times 10^{6} \mathrm{pcu} / \mathrm{hr}$. The calculated welght of an empty condenser is 7400 pounds, the tube side volume 1 s about 25 cublc feet, and the shell side volume is about 33 cubic feet. The shell side is designed for $75 \mathrm{psig}$ pressure at $65^{\circ} \mathrm{C}$, and the tube side $1 \mathrm{~s}$ designed for full vacuum at $93^{\circ} \mathrm{C}$. The shell side is hydrostatically tested at II5 psig, while the tube side is given a 25-psig hydrostatic test followed by a 20-psig "Freon" test.

\section{REBOILER SEPARATOR}

The rebolier separator (see Figure 18) which is used in Type 2 areas is a vertical cyclone separator, 2 feet 10 inches in diameter and 5 feet $7-1 / 2$ inches high. The mixed vapor and liquid feed from the reboller enters the separator through a 10-inch tangentlal inlet nozzle. This nozzle passes through a transition plece whose outlet 
Inside the cyclone is 10 inches high by 4 inches wide. An inlet baffle 14 inches high and 2 feet in $O D$, forces the gas to swirl in the 6-Inch annulus between the baffle and the shell. The gas spins down into the tank, and the "demisted" gas ascends through the inside of the 2-foot baffle and leaves through the 10-inch vapor outlet nozzle. The liquid that has been centrifuged out of the gas flows down the tank walls into a pool at the bottom of the separator. The 11quid in this pool is kept from rotating by the ant1swirl baffle. A constant level is maintained in the bottom of the separator by an automat1c level controller. The separator has a total volume of about 30.7 cublc feet and weighs about 2400 pounds when empty. The liquid holdup during operation is about 32 gallons at a normal operating level.

\section{BOTTOMS COOLER}

\section{TYPE 1 AREAS}

The bottoms cooler in several areas (see Flgure 19) is a double-pipe heat exchanger having 70 square feet of heat transfer area and a design over-all heat transfer coefficlent of about $70 \mathrm{pcu} / \mathrm{hr}-\mathrm{ft}-{ }^{\circ} \mathrm{C}$. Each of the ten sections of the mild steel cooler 1s composed of a 16-foot 3-1nch length of 3-1nch-diameter schedule 40 outer pipe whose ends are swaged down and welded to a 16-foot 6-1nch length of $1-1 / 2$ inch-dlameter schedule 40 inner pipe. The ends of the inner pipe are welded together w1th $1-1 / 2-1$ nch return bends to form a continuous flow path for the process water which flows upward through the cooler. The cooling water flows through each section (countercurrent to the process water) in the annulus between the plpes, entering at the top section and leaving at the bottiom section. The inner pipe is designed for a temperature of $85^{\circ} \mathrm{C}$ and the outer pipe for $52^{\circ} \mathrm{C}$. Both are designed for $100 \mathrm{psig}$ pressure and are hydrostatically tested at $150 \mathrm{psig}$. The cooler welghs 1900 pounds. The volume of the inner pipe is about 2.5 cub1c feet and of the annulus between the inner and outer pipe about 5.2 cublc feet.

\section{TYPE 2 AREAS}

The bottoms, cooler in other areas (see Figure 20) is a double-pass $\left(\mathrm{D}_{2} \mathrm{O}\right.$ side) shell-and-tube heat exchanger w1th double tube sheets at each end. The process water enters and leaves the same head of the heat exchanger. This head is divided into two sections by a baffle. The process water flows in one direction through the upper 20 tubes into the unbaffled head and back in the reverse direction through the lower 20 tubes. The unit contains forty 1/2-inch-OD tubes (No. 18 BWG) on a 3/4-inch triangular pitch. The tubes are 16 feet long, but only the 14-foot 10-1/2-1nch section inside the shell is exposed to cooling water and is useful for heat transfer. The heat transfer area is 43.3 square feet. The calculated welght of the empty cooler is 600 pounds, the tube side volume is about 0.8 cuble foot, and the 
shell slde volume is about 2.2 cublc feet. The shell (cooling water) side is designed for $100 \mathrm{psig}$ pressure at $38^{\circ} \mathrm{C}$, and the tube (process water) side 1 designed for full vacuum at $38^{\circ} \mathrm{C}$. The shell side $1 \mathrm{~s}$ hydrostatically tested at $150 \mathrm{psig}$, while the tube side is given a 25-psig hydrostat1c test followed by a 20-psig "Freon" test.

\section{BOTTOMS FILTERS}

The bottoms filters (stainless steel construction) remove particulate matter over 10 microns in diameter from the moderator leaving the bottoms cooler before the moderator re-enters the purification system (see Flgure 2l). The filter elements are similar to those used in the purification afterfilters. Each fliter leaf is a flat double cone, 3/8-inch thick at the center and constructed as a sandwich. A 1/32-1nch-th1ck 3-1nch-square shim with a 2-1nch-diameter hole separates the center of two stainless steel perforated plates which are spot welded together at their 10-inch OD and are spot welded to the sh1m at the ID. Two $24 \times 100$ mesh dutch weave stalnless steel screens, located on the outside of this support frame, are welded together at the1r OD. Finally, asbestos cloth discs are placed on each side of the unit and are sewed together at their $11-1 / 8-1$ nch OD with cotton blas tape and cotton thread. Twenty fliter leaves separated by $3 / 8$-inch rubber gaskets (2-inch ID and 3-inch OD) are then assembled on a 2-1nch-OD perforated tube wh1ch is then installed in the filter housing. The filter elements are compressed and the assembly is held in place by tightening the bottom nut on the inner tube or rod of the filter housing. Each filter element has a filtering area (1ncluding both sides) of 0.61 square foot, and the entire filter (20 elements) has a total filtering area of 12.2 square feet.

The f1lter vessel has a 12-1/2-1nch ID and a 12-3/4-inch $O D$ and is 21-1/8 1nches in length, with a dished bottom (inlet) and a flanged top (outlet). The vessel has a capacity of about 12 gallons and an empty weight of 300 pounds. The filters are designed for a pressure of $110 \mathrm{ps} 1 \mathrm{~g}$ and a temperature of $110^{\circ} \mathrm{F}$, and are hydrostatically tested at $150 \mathrm{psig}$.

The moderator flows from the outside of the filter element, through the asbestos cloth which removes particles larger than 10 microns. If the fraglie asbestos cloth becomes defectlve during assembly or use, the $24 \times 100$-mesh screen fllters out the larger particles. The filtered moderator then passes into the perforated tube and out of the vessel through the exit Ine.

\section{RUNDOWN :TANKS}

Each area has two rundown tanks (see Figure 22), which are used to hold the contents of the respective ( $A$ or $B$ ) columns when the column is not operating. These horizontal tanks are 4 feet in diameter and 
9 feet 4-5/8 1nches in over-all length, with an 8-foot-long cylindrical section between the tangent lines on the dished heads. Each tank welghs about 2400 pounds when empty and holds 800 gallons when full.

\section{VACUUM PUMP SYSTEM}

The vacuum pump (see Figure 23) is a Nash Englneering Co. type TS-8-I2 two-stage untt, w1th a capac1ty (F1gure 30) of at least $55 \mathrm{cfm}$ (measured at suction side vacuum) at pressures greater than the operating absolute pressure of $100 \mathrm{~mm} \mathrm{Hg}$ (vacuum). Both stages are driven on a common shaft by a 5-hp, 1750-rpm motor. Mechanlcal shaft seals (Durametallic Co.) are installed on both sides of the high pressure stage and on the drive end of the low pressure stage.

The Nash pump consists of an elliptical housing inslde which a cylindrical rotor revolves, rotating and centrifuging the I1quid around the casing. A sufficient amount of liquid is maintained in the pump to fust seal the impeller at 1ts points of greatest clearance from the casing.* The rotating liquid therefore alternately advances toward and recedes from the center of the 1mpeller, acting essentlally as a series of liquid pistons. As the liquid recedes, gas is sucked in through the inlet ports and as the liquid advances, the gas is compressed and discharged into the outlet ports.

The Nash vacuum pump using moderator as sealing liquid was selected since 1t had ample capacity and offered greater insurance against contamination with o1l (such as is generally used in other vacuum pumps) or w1th light water or steam (used in vacuum jets).

The gas and liquid leaving the pump are discharged 1nto a centrifugal separator (see Figure 24). Since the gas pumping rate is constant at about $55 \mathrm{cfm}$, most of the gas is returned to the columns by the automatic pressure controller, and only the excess gas (which has leaked into the columns) is vented out of the system through a vent gas rotameter. The disentrained liquid from this centrifugal separator recirculates through the column vacuum pump cooler to the two stages of the pump at a rate regulated by limiting orlfices built into the pump. A constant liquid level is maintained in the pump by an automatlc float-type level control.

The column vacuum pump cooler (see Flgure 25) is a double-pipe heat exchanger having a heat transfer area of about 0.22 square foot. Each of the nine sections contain 5 feet of 1-1/4-1nch schedule 80 steel pipe (through which the process water flows) enclosed in 5 feet

* Since some Ilquid continuously evaporates or entrains into the gas beling pumped, a small stream of seal liquid must be fed continuously to each stage of the pump. 
of 2-inch schedule 40 steel pipe (the cooling water flows through the annulus between these pipes). The unit is designed for $70^{\circ} \mathrm{C}$ temperature, process-water-side pressures between atmospherlc and full vacuum, and a cooling water pressure of 100 psig. Both sides are given a 150-psig hydrostatic test.

\section{VENT DRYING SYSTEM}

The gas removed from the columns by the vacuum pumps contains a small amount of moderator (about 7 vol $\%$ at a gas temperature of $40^{\circ} \mathrm{C}$ ). Before this gas is exhausted to the atmosphere via the stack, the molsture is removed either in a refrigerated condenser (Type 1 Areas) or an alumina gel dryer (Type 2 Areas). At the maximum rate of a1r inleakage specified in the standard procedures (200 cub1c feet per day) and a separator exit temperature of $40^{\circ} \mathrm{C}$, less than $3 / 4$ pound of $\mathrm{D}_{2} \mathrm{O}$ per day is contained in the vent gas and $1 \mathrm{~s}$ avallable for recovery.

TYPE I AREAS

The two vent condensers in these areas are plped in parallel and are used alternately (see Figure 26). Each condenser is a double-tubesheet shell-and-tube heat exchanger with the vent gas passing through the tubes. The shell side is designed for $250 \mathrm{psig}$ at $120^{\circ} \mathrm{C}$ and for full vacuum at $-30^{\circ} \mathrm{C}$, and the tube side is designed for fiull vacuum at $-30^{\circ} \mathrm{C}$. The 314 tubes ( 1 inch oD $x 5$ feet long $x$ No. 16 BWG) are spaced on a 1-3/8-inch triangular pattern. The heat transfer area of the 30-3/4-inch length contacted by the refrigerant is 183 square feet. Each condenser welghs 2800 pounds when empty and has a tube side gas volume of about 21 cubic feet and a shell side capacity of about 6.5 cublc feet. The ammonia refrigerant used in the shell has a nominal operating temperature of $-20^{\circ} \mathrm{C}$.

\section{TYPE 2 AREAS}

The vent gas drying system in these other areas is a standard Pittsburgh "Lectrodryer" (type BWC, size 150-SP) (see F1gure 27). The vent gas passes through one of two alternately used units, where the molsture present is physically adsorbed on the alumina gel to produce an effluent gas (golng to the stack) with a dew point colder than $-35^{\circ} \mathrm{C}$. When one alumina gel dryer becomes saturated with molsture, it is taken out of service and the alternate dryer is put into use. The heavy water is recovered by indirectly heating the alumina gel with steam in the embedded steam colls and recirculating gas through the alumina gel and then through a condenser and back through the alumina gel. After all the heavy water has been removed, the regeneration cycle is stopped and the alumina gel is cooled by passing water through the steam colls. The dryer is then ready for use. 
This drying system is designed for a maximum pressure of $15 \mathrm{ps} 1 \mathrm{~g}$, a working pressure of $1 \mathrm{psig}$, an average flow of 10 pounds per hour, an influent dew point of $43^{\circ} \mathrm{C}$, and an effluent dew point of $-35^{\circ} \mathrm{C}$.

\section{MISCELLANEOUS PUMPS*}

A first-stage bottoms (centrifugal closed impeller) pump is used in Type I Areas during normal distillation to pump the A bottoms product from the A column through the $A$ bottoms cooler and into the surge tank.** This pump is also used as a feed pump during operation at total reflux to recirculate materlal from the bottom of A column back to the A reboller.

Two second stage bottoms (centrifugal closed impeller) pumps in each area, piped in parallel, are used alternately to pump the B column bottoms from B column to the top of A column for use as A column reflux. These pumps are also used to transfer material from the A rundown tank to A column when starting up A column.

Two second stage condensate (centrifugal closed impeller) pumps in each area, plped in parallel, are used alternately to pump most of the condensate from the $B$ condenser back to the top of $B$ column for use as $B$ column reflux while simultaneously pumping the small drawoff stream ( 1.5 to $14 \mathrm{lb} / \mathrm{hr}$ ) through the drawoff rotameter to the drumming station. Moderator from this stream is pumped periodically to the vacuum pump separator to maintain the desired operating level. The nominally idle pump is used to drain the excess moderator, which has overflowed from the vacuum pump separator, into collection drums. (Since this overflow may be diluted with light water if there is a leak in the column vacuum pump cooler or in the mechanical seal cooling system, $1 t$ is returned to the moderator system only after analysis has shown the 1sotopic purity to exceed $99.0 \% \mathrm{D}_{2} \mathrm{O}$.) These second stage condensate pumps are also used when starting up the distillation system to pump moderator from the $B$ rundown tank into the bottom of $B$ column.

During batch distillation the nominally 1dle second stage condensate pump is used to recirculate the bottoms from $A$ column into the $A$ rundown tank, and the nominally idle second stage bottoms pump is used to pump the moderator from the A rundown tank into the A reboller.

A purge pump is provided in Type 2 Areas to remove liquid with a high concentration of contaminants from the closed reboller - rebollerseparator system to the purification evaporator or to a drum. Since

* Specifications for these pumps are shown in the table on page 25.

* In Type 2 Areas, the bottoms product flows to the coolant return tank by gravity. 
the suction side of this pump is at about 300 to $350 \mathrm{~mm} \mathrm{Hg}$ absolute pressure, a positive displacement pump is used. The Lapp "Pulsafeeder" pump (F1gure 28) uses a reclprocating piston (w1th a variable stroke length to vary flow rate) to create a cyclic pressure in the completely enclosed primary fluid and thus to move a rubber diaphragm back and forth. The process fluid side of the diaphragm is provided with inlet and outlet valves; thus when the rubber diaphragm flexes cyclically the process fluid is pumped through the system. This type of pump will not contaminate the process fluld, since all lubricated parts can be kept in the primary fluid section of the pump and out of the process fluid system. As an additional precaution against contamination of moderator by oll in case the diaphragm ruptures, an intermediate fluid chamber contalning water is used.

A condensate metering pump is provided for each area to pump moderator into the secondary feed points in both columns. Since a constant flow rate (of varlable quantity) is needed to prevent upsetting column operation, a Lapp "Pulsafeeder" is also provided for this service.

Pump List

\begin{tabular}{|c|c|c|c|c|c|c|c|}
\hline \multirow[b]{2}{*}{ Identification } & \multirow{2}{*}{$\begin{array}{l}\text { No./ } \\
\text { Area } \\
\end{array}$} & \multirow[b]{2}{*}{ Areas } & \multirow[b]{2}{*}{ Capac1ty } & \multirow[b]{2}{*}{ Head } & \multicolumn{2}{|c|}{ Motor } & \multirow{2}{*}{$\begin{array}{l}\text { Mfr \& } \\
\text { Model }\end{array}$} \\
\hline & & & & & $\mathrm{hp}$ & $\mathrm{rpm}$ & \\
\hline $\begin{array}{l}\text { Ist-Stage } \\
\text { Bottoms Pump }\end{array}$ & 1 & Type 1) & & & & & \\
\hline 2nd-Stage & & & & & & & \\
\hline Bottoms Pump & 2 & A.II & $70 \mathrm{gpm} *$ & $113 \mathrm{ft}$ & 3 & 3450 & $\begin{array}{l}\text { Ingersoll } \\
\text { Rand } \\
1 \text { CRV }\end{array}$ \\
\hline $\begin{array}{l}\text { 2nd-Stage Con- } \\
\text { densate Pump }\end{array}$ & 2 & All & & & & & \\
\hline Purge Pump & 1 & Type 2 & $\begin{array}{l}0 \text { to } \\
11.9 \mathrm{gph}\end{array}$ & - & $1 / 3$ & 1750 & $\begin{array}{l}\text { Lapp } \\
\text { CPS-1 }\end{array}$ \\
\hline $\begin{array}{l}\text { Condensate } \\
\text { Metering Pump }\end{array}$ & 1 & AlI & $\begin{array}{l}0 \text { to } \\
2.9 \mathrm{gph}\end{array}$ & - & $1 / 3$ & 1750 & $\begin{array}{l}\text { Lapp } \\
\text { CPS-1 }\end{array}$ \\
\hline Vacuum Pump & 2 & All & $55 \mathrm{cfm} * *$ & $\begin{array}{l}0-28 " \\
\mathrm{Hg} \text { vac }\end{array}$ & 5 & 1750 & $\begin{array}{l}\text { Nash } \\
\text { TS-8-L2 }\end{array}$ \\
\hline
\end{tabular}

* For a typlcal characterist1c curve, see figure 29. * For a typical characteristic curve, see figure 30. 


\section{INSTRUMENTATIION}

Flow

The primary feed to A column is measured with an orifice-type flow recorder in all areas. The moderator level in the line below the bottom of A column in Type 1 Areas and in the reboller separator in Type 2 Areas is automatically malntained by a level controller which admits feed to the rebolier at the rate required to keep the level constant.

The flow of moderator from the bottom of A column back to purification in all areas is measured with an orifice-type flow recorder. In Type 1 Areas this recorder is also a controller which is used to control the flow at $7 \mathrm{gpm}$. In Type 2 Areas, all liquid flowing to the bottom of A column drains back by gravity to the coolant return tank (described in "Moderator Feed Control" and "Reboller Level" on page 33 ).

The steam flow to $A$ and $B$ rebollers in all areas is controlled with a stean flow recorder. The condensate from the reboller jackets is automatically drained by bellows-type thermostatic traps.

Rotameters are used to measure the reflux (condensate return) rate to both columns, the rate at which inerts are vented from the system, and the $B$ overheads product drawoff rate. The total amount of product removed and collected in the drum is welghed on a scale.

\section{$\underline{\text { Level }}$}

Float-type level controls are used to maintain a constant level in the $A$ and $B$ condensers in all areas, in the line below $B$ column in all areas, in the line below A column in Type 1 Areas, and in the reboller separator in Type 2 Areas. These controllers operate an automatic valve which controls the rate at which moderator is being transferred from the polnt being controlled to the next part of the system.

A float-type level controller is used in the vacuum pump separator to keep the liquid level from exceeding the desired value. This excess material drains into a drum in Type 1 Areas or in a 6-inch-pipe collection chamber in Type 2 Areas and is returned to the system. Th1s material is analyzed periodically to determine whether light water is leaking into the distillation system from the vacuum pump cooler or vacuum pump seals.

The level in each rundown tank is determined by bubbling air through a dip tube and measuring the differential pressure.

The 6-inch-pipe collection chamber in Type 2 areas (for overflow from the vacuum pump separator) is equipped with a level recorder-controller 
which presently is used as an indicator only. (This recordercontroller was designed to start and stop the pump automatically, thus keepling the collecting chamber empty: This pump discharges to the suction of the second stage bottoms pump or the second stage condensate pump.)

\section{Pressure and Pressure Drop}

A pressure controller is located in the gas line between the column and condenser for both $\mathrm{A}$ column and $\mathrm{B}$ column. When the absolute pressure exceeds $150 \mathrm{~mm} \mathrm{Hg}$, an alarm sounds and the unit is isolated from the reactor. When the pressure reaches 1 psig, the steam flow to the corresponding rebolier is automatically shut off and the isolation valves in the moderator feed and return lines are automatically closed.

The pressure drop across each column is measured with a differential pressure recorder. This pressure drop increases with increase in steam rate, and when excessively high indicates that the column is flooded.

The vacuum in the entire distillation system is controlled by a pressure recorder-controller measuring the pressure in the common suction line to both vacuum pumps. Since these pumps have excess capacity, some gas is continuously bypassed from the discharge to the suction side of the pump to prevent the absolute pressure from becoming too low. Indicating vacuum gages are also installed to measure the vacuum in the common line to the suction of the vacuum pumps.

Pressure gages are installed on the discharge piping of each first and second stage bottoms pump and on each second stage condensate pump.

\section{Temperature}

Temperature recorder-controllers are installed on each column condenser and on the bottoms cooler to control the temperature of the effluent process water at the desired value by throttling the cooling water flow.

Temperature indicators are used to indicate the temperature of the vapor entering the $A$ and $B$ condensers.

\section{Power Failure}

Instmmentation is provided so that an electrical power fallure will close automatic solenold valves at the suction of the vacuum pumps and prevent immediate loss of vacuum. Such a power fallure will also close the steam admission valves to the reboller, which in turn will operate the 1solation switch and close the distillation system feed and return valves. 


\section{Radiation}

A radiation-recording instrument, located in the feed Iine to A column from the purification system, is used to prevent the unshielded distillation equipment from becoming excessively radioactive. If the radiation becomes excessive, the distillation system feed and return valves (1solation valves) are automatically closed.

\section{Conductivity}

A conductivity-recording instrument is provided in the feed line to prevent dissolved contaminants (which might cause corrosion) from entering the distillation system. If the conductivity becomes excessive, the distillation system feed and return valves (1solation valves) are automatically closed.

\section{Specific Gravity}

A continuous specific gravity instrument ("Densitrol") measures the isotopic purity of the moderator being returned to the coolant return tank from distillation. An 1sotopic purity lower than that of the influent feed moderator indicates a leak of light water from a reboller, condenser, or cooler, and automatically closes the isolation valves (distillation feed and return valves).

\section{Isolation Switch}

An isolation switch is provided to enable the operator to shut down the distillation system rapidly by closing the isolation valves (the distillation system feed and return valves). Th1s switch can be operated manually by the operator and is automaticaliy operated by instruments in case of insufficient vacuum ( $>150 \mathrm{~mm} \mathrm{Hg})$ in the columns, high conductivity ( $>5$ micromhos) or high activity ( $>19 \mathrm{mr} / \mathrm{hr}$ ) in the feed moderator, low isotopic purity (below $99.4 \mathrm{~mol} \% \mathrm{D}_{2} \mathrm{O}$ ), or high temperature (above $50^{\circ} \mathrm{C}$ ) in the moderator being returned to purification, or a reduction in steam rate of more than 200 pounds per hour.

\section{OPERATION}

The distillation systems can be operated elther as continuous stills to remove light water from the moderator in the reactor or as batch stills to increase the light water concentration and decrease the tritium concentration of moderator previously removed from the reactor system. The single basic method of operation for both cases Is shown in the flowsheets for Type 1 Areas (FIgure 1) and Type 2 Areas (Figure 2); the differences involve malnly the method of introducing the feed and removing the products. 


\section{STARTUP}

$B$ column and A column are started up separately on total reflux, and then are operated on total reflux as a coordinated unit. This startup procedure is outlined in the following paragraphs.

The two columns and their auxiliary equipment are lsolated from each other, and the amount of moderator required for each column (about 5000 pounds) is charged to each rundown tank. B column is started first. The vacuum pump and vent condenser are put into operation, and the pressure in $B$ column is reduced to the desired operating value ( $100 \mathrm{~mm} \mathrm{Hg}$ absolute pressure). The $B$ column condenser and the A bottoms cooler are then put into operation by turning on the cooling water. The $B$ reboller is fllled up to 1 ts normal operating level with moderator from the $B$ rundown tank, and a small flow of steam is fed to the shell side of the $B$ reboller, causing the moderator to boll out of the rebolier and into the column. Additional moderator is pumped up from the $B$ rundown tank at the rate required to keep the reboller level constant at the operating level. The moderator vapor rises up the column, heats it. to operating temperature, finally reaches the $B$ condenser, and is condensed. When the level in the condenser reaches the operating level, the second-stage condensate pump is started, and the condensate level is maintained constant by pumping excess condensate back to the top of $B$ column to serve as $B$ column reflux. The steam flow rate to the $B$ reboller is slowly Increased to $3000 \mathrm{lb} / \mathrm{hr}$ and the column operated at these conditions long enough to make sure the controls and equipment are operating properly.

The A column is now placed in operation in the same manner. After the individual columns are operating satisfactorily, they are interconnected so that the A column condensate passes through the $B$ reboller (where it is mixed with the reflux at the bottom of $B$ column and partially vaporized) before belng returned to the top of A column to serve as A column reflux. The entire system is then operated as a coordinated unit until smooth operation of the equipment and controls has been demonstrated, and equilibrium has been achieved.* The distillation system is now ready to be put into productive operation.

\section{NORMAL DISTILLATION}

The system is ready to be put into use as a normal distillation system as soon as the heavy water concentration in A column bottoms is at least $0.05 \mathrm{~mol} \% \mathrm{~h}$ igher than that in the moderator circulating through the reactor. If the equilibrium total reflux A bottoms

* The equilibrium concentrations at the top of $B$ column and the bottom of A column at total reflux are shown in F1gure 31 . 
concentration is not this high, sufficient light water (as indicated by Figure 32 ) to attaln this concentration $1 \mathrm{~s}$ removed from the system as $B$ overheads product and the system is operated at total reflux. When the desired A bottoms concentration has been attalned, moderator clrculation from purlfication to the A reboller and from the A bottoms cooler back to purification is inltlated by opening the feed and return valves and closing the bypass valve (through whlch moderator circulates when distillation is operated at total reflux while 1solated from the reactor system). The system is then operated at total reflux (but with a bottoms feed) unt1l the $B$ overheads concentration drops to the value it will have at the desired drawoff rate (as indicated by F1gure 33). If the $B$ overheads concentration decreases beyond this value, sufficlent B overheads product (as indicated by Figure 34 ) to attain this value is removed. The desired amount of $B$ overheads product is then removed batchwise from the system once each shift. The system is now operating as a normal distillation system on a continuous basis.

\section{SHUTDOWN}

The distillation system is 1solated from the reactor moderator system by closing the feed and return valves and is then put on total reflux by opening the bypass valve. B column is then 1solated from A column, and each $1 \mathrm{~s}$ placed on total reflux. If the moderator is to be drained out of a column, the valve in the suction line to the vacuum pump is closed and the vacuum is broken (replaced) with helium. The steam is then shut off, the moderator is drained to the rundown tank, and the cooling water flow to the condensers and coolers is stopped. While the columns are not operating, a positive helium pressure is maintained to prevent corrosion of the mild steel equipment.

\section{BATCH DISTILLATION}

The production rate for batch distillation charges using only the normal holdup (100 gallons) in the bottom of A column and A reboller is undesirably low. Th1s holdup, therefore, is increased by using the A rundown tank to hold A bottoms moderator. (The spare secondstage condensate pump is used to transfer the moderator from the bottom of A column into the A rundown tank, and the spare secondstage bottoms pump is used to transfer the moderator from the A rundown tank to the A column feed control valve. The level of moderator in the line below A column is malntalned constant by throttling the valve at the discharge of the spare second-stage condensate pump.)

A batch distillation cycle is inltiated by starting up B column on total reflux (as described on page 29), using the moderator contained in the $B$ column at the end of the previous charge. The moderator contained in A column and in the A rundown tank during the previous charge is put into drums. About 12,000 pounds of degraded moderator 
is then charged into A column and the A rundown tank, and A column is started up on total reflux. The two colums are then operated at total reflux as a unit until the $B$ overheads concentration drops to 45 mol \% $\mathrm{D}_{2} \mathrm{O}$, whereupon drawoff is started (the overheads product is removed at the rate required to keep the $B$ overheads concentration constant at $\left.45 \mathrm{~mol} \% \mathrm{D}_{2} \mathrm{O}\right)$. During this slow drawoff period, an intermediate feed of degraded moderator is added to the correct plate of A column (as indicated by Figure 35) at the same rate at which $B$ overheads product is being removed. When the drawoff rate required to maintain the $B$ overheads concentration at the desired value ( 45 mol $\% \mathrm{D}_{2} \mathrm{O}$ ) drops below $5 \mathrm{lb} / \mathrm{hr}$, intermediate feed and drawoff are discontinued. The overheads product removed up to this point is reconcentrated in the heavy water production area.

The average concentration of the moderator in $A$ column and mundown tank is now ralsed to $99.3 \mathrm{~mol} \% \mathrm{D}_{2} \mathrm{O}$ by removing the required quantity of overheads product (as rapidly as possible) and allowing the system to operate at total reflux until it comes to equilibrium. The tritium content of this rapid drawoff product is too high for efficient processing in the heavy water processing area and therefore is recycled in the next batch distillation charge. When the average concentration of $\mathrm{A}$ column and rundown tank has reached 99.3 mol $\phi_{0} \mathrm{D}_{2} \mathrm{O}$, $B$ column and A column are isolated and operated individually on total reflux. A column is then shut down, and the moderator contained in A column and rundown tank is put into drums and returned to the reactor. In Type 2 Areas, the moderator from the A reboller and separator (which contains all the solid and dissolved impurities contained in the degraded moderator charged to the batch distillation facility) is put into special drums, and processed as indicated by analysis before being returned to the reactor. In Type 1 Areas, the moderator in the A reboller continuously circulates through the bottom of $\mathrm{A}$ column and is drained and processed in the same manner as the contents of A column.

\section{DIFFERENCES IN THE TWO TYPES OF DISTILLATION SYSTEMS}

The distillation systems in Type 1 Areas differ from those in Type 2 Areas in three respects: the vent drying system, the A column vaporlzer and evaporator system, and the A column feed control system. Equipment differences are detalled in the Equipment section of this report (starting on page 17). The present section discusses operating differences.

\section{VENT DRYING SYSTEM}

The noncondensable gases removed from the distillation system by the vacuum pumps contain small amounts of heavy water vapor. In Type 1 Areas this heavy water is condensed out of the gas in ammoniarefrigerated condensers. Two condensers are provided. When the ice and snow layer becomes thick enough to decrease the heat transfer 
capactty and gas pressure drop of one condenser, the spare condenser is put into operation and the moderator is recovered from the frozen, plugged condenser by thawing with warm ammonia.

In Type 2 Areas, recovery of moderator is accomplished w1th a pain of alumina gel dryers. When the alumina in one unit becomes saturated w1th molsture, the other unit is placed in operation. The moderator is then recovered by heating the saturated alumina and recirculating helium through the alumina and through a condenser until no more moderator can be recovered.

THE A COLUMN VAPORIZER SYSTEM*

In Type 1 Areas, the bottom of A column is connected to the A reboller with a 6-inch line. Steam flow to the A rebolier jacket causes the moderator in the tubes to boll and creates a gas lift causing the moderator to recirculate rapldiy through the bottom of $A$ column and through the 6-inch connecting line and the A reboller. Vaporized moderator ascends the column, and an equal amount of reflux descends into the bottom of A column. A constant moderator level is maintained in the line below A column by a level controller which regulates the amount of moderator admitted to $A$ column. The rate at which $A$ bottoms is pumped back to the circulating moderator system after being cooled in the bottoms cooler and filtered in a column filter is controlled at $7 \mathrm{gpm}$ by an automatic flow controller.

The separator (not included in Type 1 Areas) located between the A reboller and A column enables the Type 2 Area A reboller-separator combination to act as an evaporator. All reflux dropping to the bottom of A column is returned by gravity (not pumped as in Type I Areas) to the coolant return tank after being cooled and filtered. Thus there is never any liquid in the bottom of A column. A constant I1quid level is maintained in the A separator (not in the line below A column as in Type 1 Areas). Steam flow to the rebolier jacket causes the moderator to boll and creates a gas lift causing the moderator to recirculate rapidly through the separator, the 6-inch connecting line, and the reboller. The vapor formed enters the bottom of A column through the 10-1nch gas exit line from the separator and ascends A column, but there is no provision for liquid to leave the A reboller-separator combination during operation. Thus insoluble and soluble nonvolatile materials in the moderator fed to the reboller will be concentrated in the circulating moderator stream in the A separator. To prevent the concentration of these materials from becoming excesslve and to provide a method of removing these contaminants from the system, a small amount of moderator is

* The $B$ reboller and $B$ column equipment is the same in all areas. 
perlodically removed from the A reboller-separator system by the rebolier purge pump.

MODERATOR FEED CONTROL

The moderator feed rate from purification into the A reboller is controlled by the rate at whlch moderator leaves the reboller.* In Type I Areas, a flow controller maintalns a $7 \mathrm{gpm}$ flow out of the reboller. In Type 2. Areas, where the only way moderator can leave the reboller-separator system is by evaporation, this return flow rate is controlled by the steam flow rate to the reboller.** Thus the moderator feed rate in Type 2 Areas w1ll be equal to the vaporization rate as long as the level controller maintains a constant level in the separator. The rate at which A column bottoms is returned to the purification system (as shown on the flow indicator) is actually controlled by the rate at which reflux descends A column, since there is no liquid holdup in the bottom of A column. The configuration of the return plping serves as a vacuum seal and prevents the admission of air to the distillation system.

\section{REBOILER LEVEL}

A true Ilquid level cannot exist in a reboller during operation since the rebolier acts as a combined gas lift and thermal siphon, causing each reboller tube to contain a mixture of 11 quid and vapor slugs rising through the tube at a very high rate. The pressure at the bottom of the reboller (the head of liquid and gas above the bottom of the reboller plus the pressure drop required to propel the liquid and gas up through the tube) will equal the liquid head avallable at the same elevation in the separator (Type 2) or in the line below A column (Type 1). As the vaporization rate increases, the pressure drop in the tube increases and the amount of liquid in the tube decreases. Thus although the indicated liquid level remains constant, the amount of liquid in the rebolier tubes is an inverse function of the steam flow rate. The indicated liquid level, however, accurately reflects the liquid level at the point of measurement. (The 6" Iine. below the distillation column in Type 1 Areas and the reboller separator in Type 2 Areas.)

* The rate at which moderator is admitted to the reboller is automatically controlled by a level controller which maintains a constant level in the reboller separator (Type 2) or in the line below A column (Type l).

* A steam flow of $3000 \mathrm{lb} / \mathrm{hr}$ wlll produce a feed rate of about $5.0 \mathrm{gpm}$. 


\section{LIGHT WATER AND AIR INLEAKAGE}

Light water inleakage into the stills directly reduces the capacity of the distillation system to remove light water from the reactor. The amount, if any, of inleakage can be determined by operating at total reflux and determining the rate at which the isotopic purity of A bottoms, B bottoms, and B overheads decreases. The probable sources of inleakage are the water-cooled or steam-heated heat exchangers.

The amount of air inleakage can be estimated by measuring the rate at which inerts are vented from the distillation system to the stack. Since the quantity of inerts dissolved in the moderator and bolled off during distillation is very small, the vent gas can be assumed to be derlved from alr inleakage. The humidity of this air introduces ifght water into the system in amounts which on a humid summer day could be equal to the normal light water production rate of 4 pounds per day. Therefore, the empty system is tested for air inleakage and is not put into operation if, when isolated from the vacuum pumps, the pressure rises (vacuum drops) over $3 \mathrm{~mm} \mathrm{Hg}$ per hour from an initial value of $100 \mathrm{~mm} \mathrm{Hg}$ absolute pressure (190 cublc feet per day or about $0.30 \mathrm{Ib} \mathrm{H}_{2} \mathrm{O}$ per day for air having a temperature of $80^{\circ} \mathrm{F}$ and a relative humidity of 100\%). The normal amount of a1r inleakage experienced during operation as read on the vent rotameter is about 100 cublc feet per day.

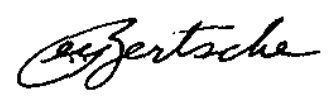

E. C. Bertsche Reactor Technology Section

\section{BIBLIOGRAPHY}

Badger, W. L. and McCabe, W. L. Elements of Chemical Engineering. New York, McGraw-H1l, (1931), Chapter V: "Evaporation;" Chapter IX: "Distillation."

Kirchenbaum, I. Physical Properties and Analysis of Heavy Water. New York, McGraw-Hil1, (1951).

Robinson, C. S. and Gilliland, E. R. Elements of Fractional Distiliation. New York, McGraw-H1lI, (1950).

Walker, W. H., Lewis, W. K., McAdams, W. H., and G1l11land, E. R. Principles of Chemical Engineering. New York, McGraw-H111, (1937), Chapter XIII: "Evaporation;" Chapter XVI: "Distillation." 


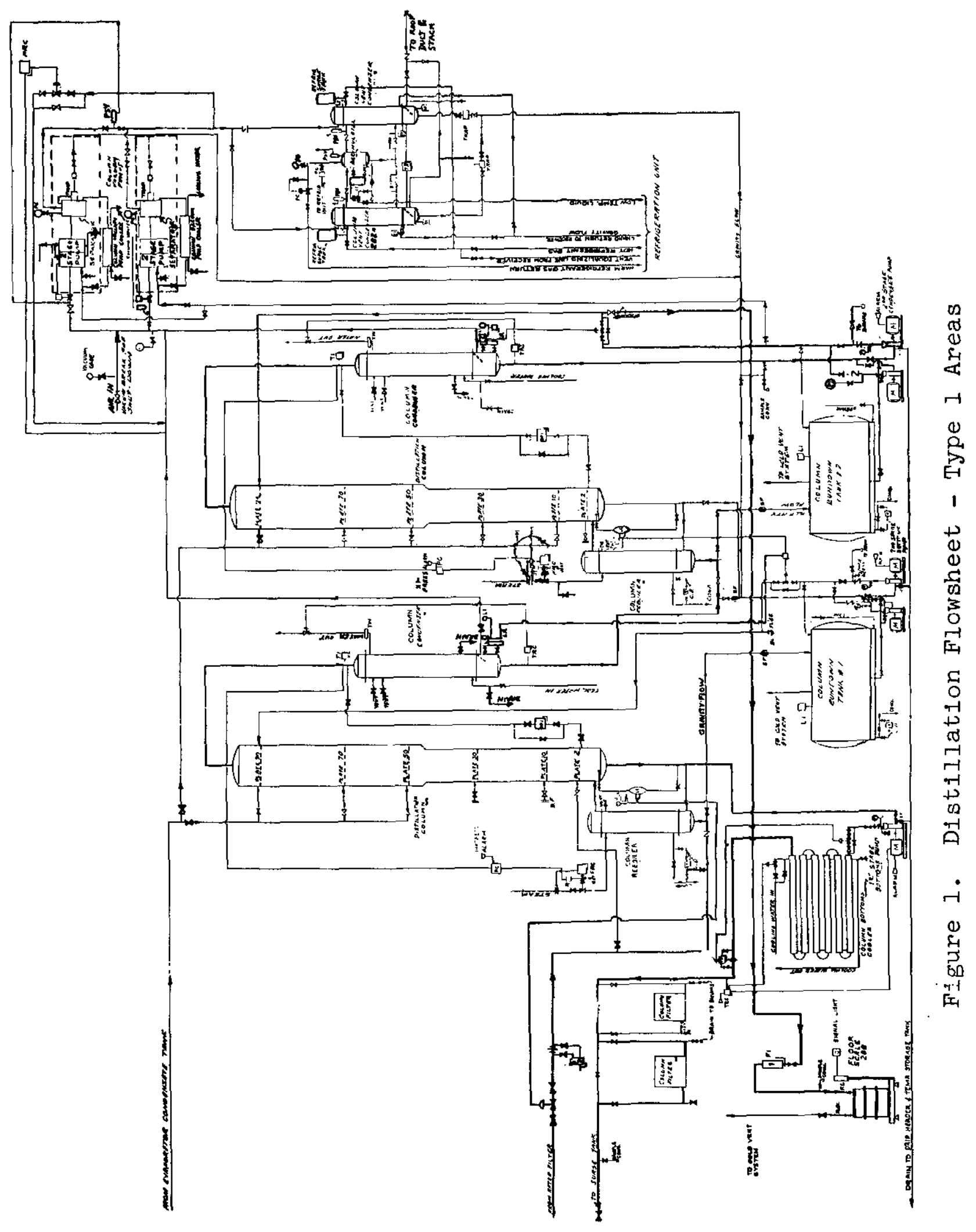




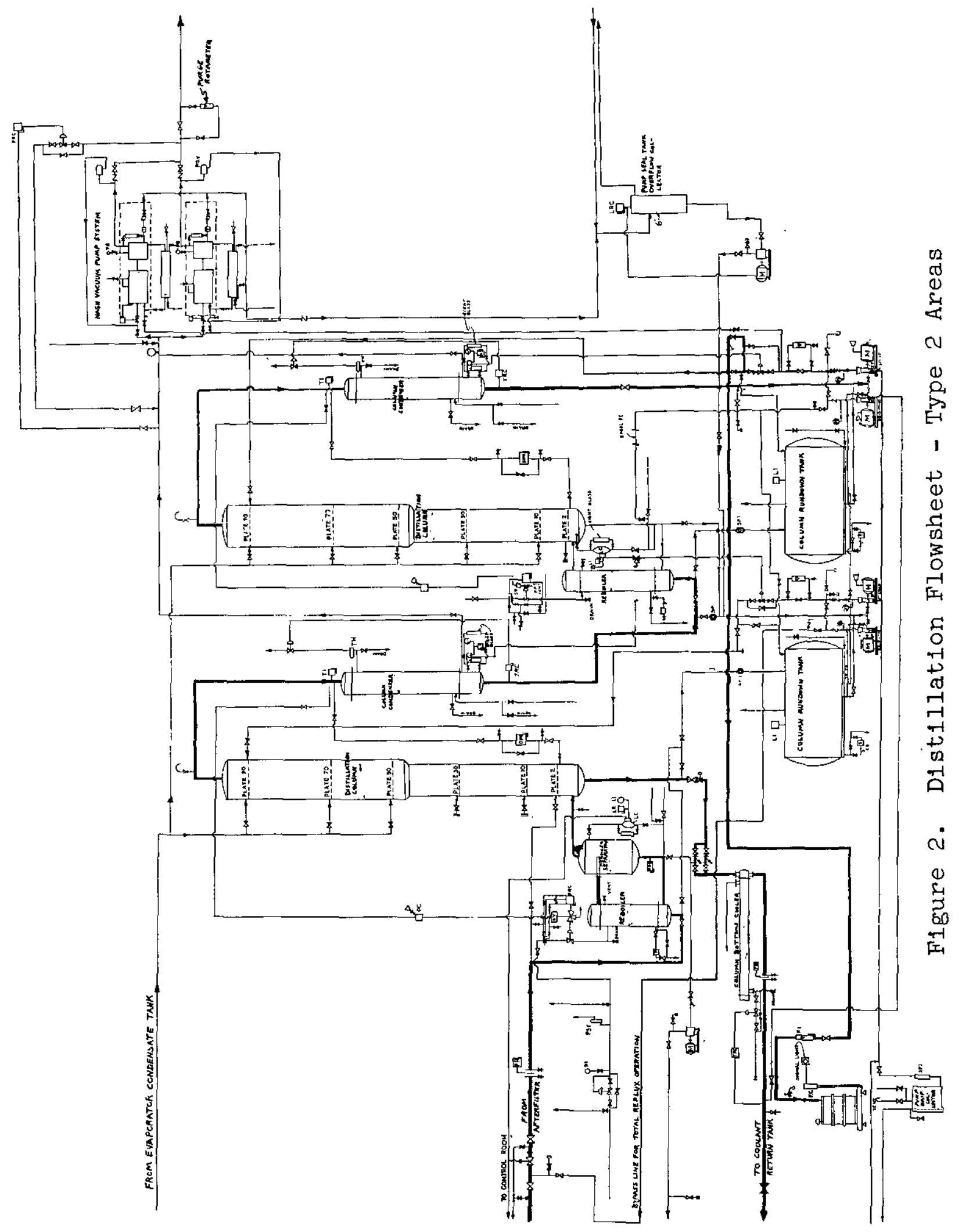




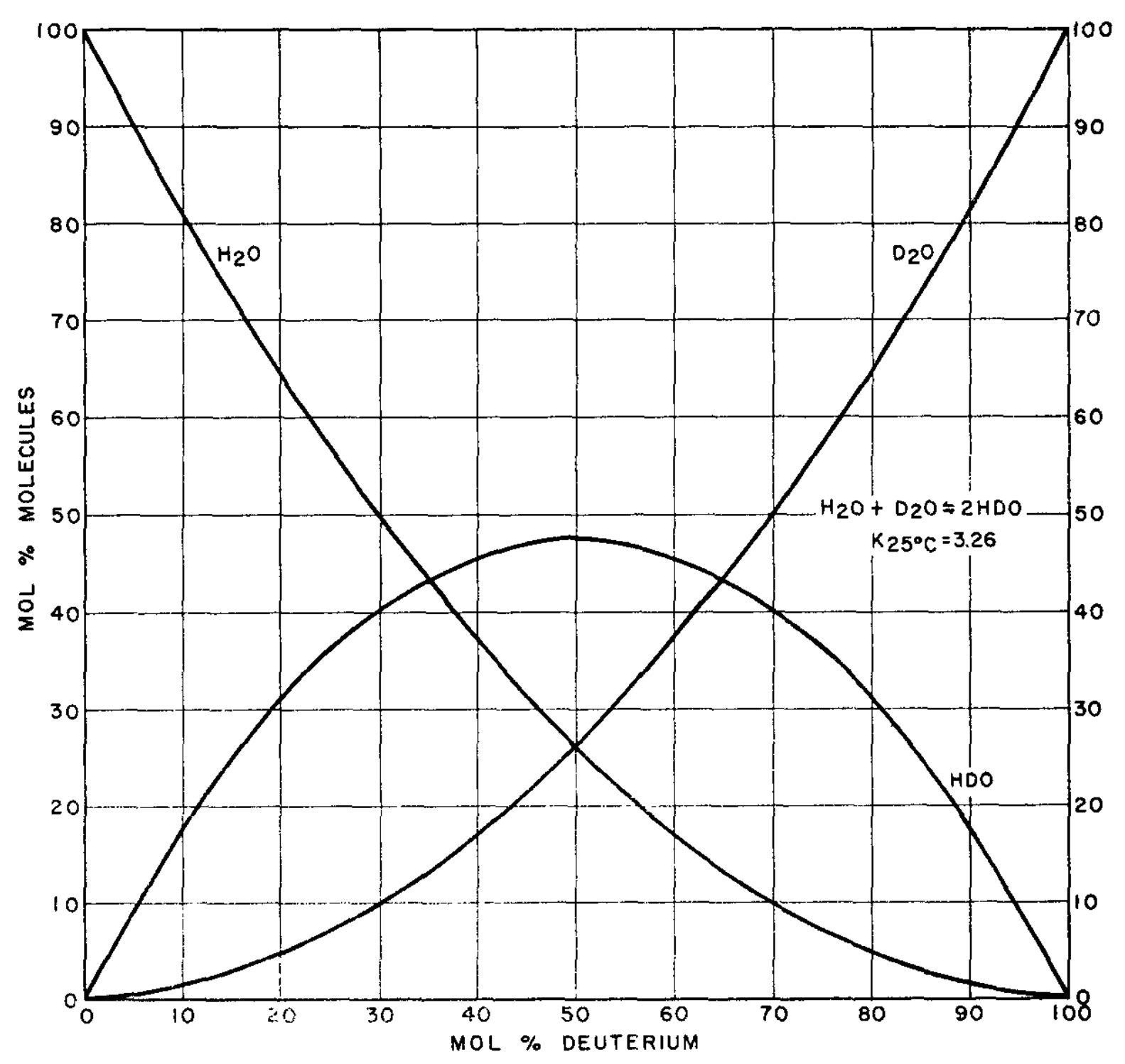

Figure 3. Equilibrium Concentrations of $\mathrm{H}_{2} \mathrm{O}, \mathrm{D}_{2} \mathrm{O}$, and $\mathrm{HDO}$ vs Over-all Concentration of $\mathrm{D}_{2} \mathrm{O}$ in Water 


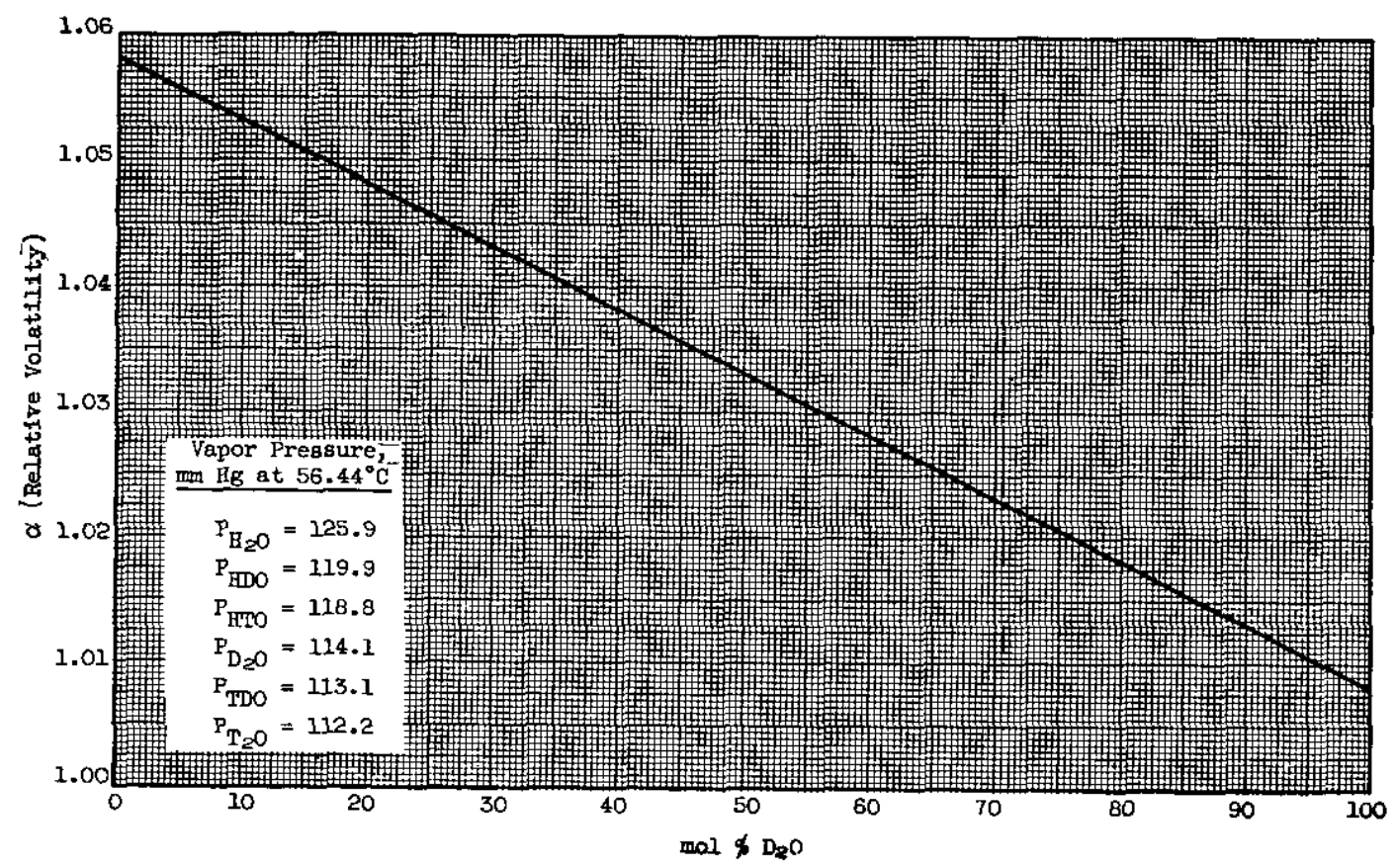

Figure 4. Simplified Relative Volatility Curve for $\mathrm{T}_{2} \mathrm{O}$ in $\mathrm{D}_{2} \mathrm{O}-\mathrm{H}_{2} \mathrm{O}$ Mixtures

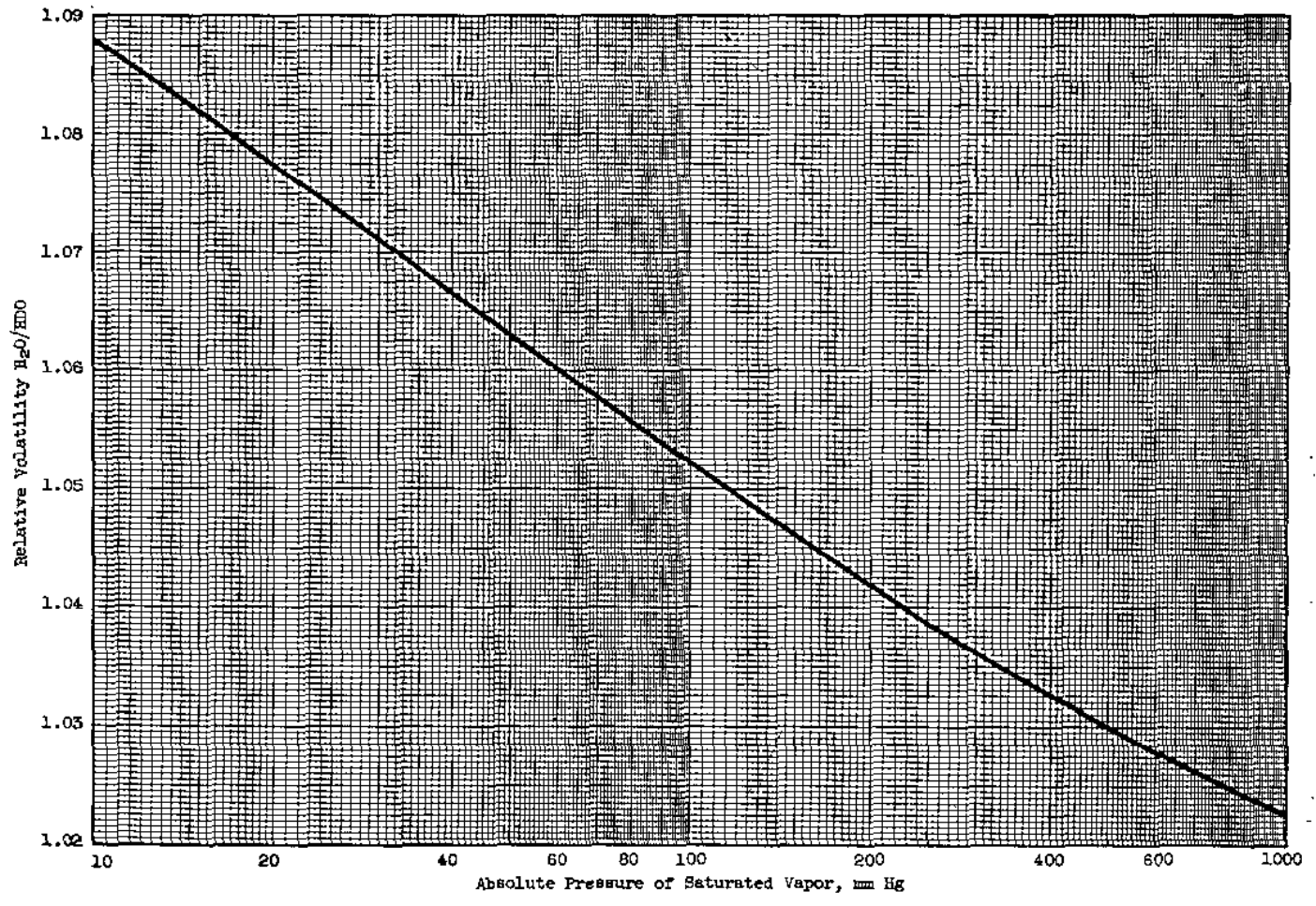

F1gure 5. Relative Volatility of $\mathrm{H}_{2} \mathrm{O} / \mathrm{HDO}$ vs Vapor Pressure 


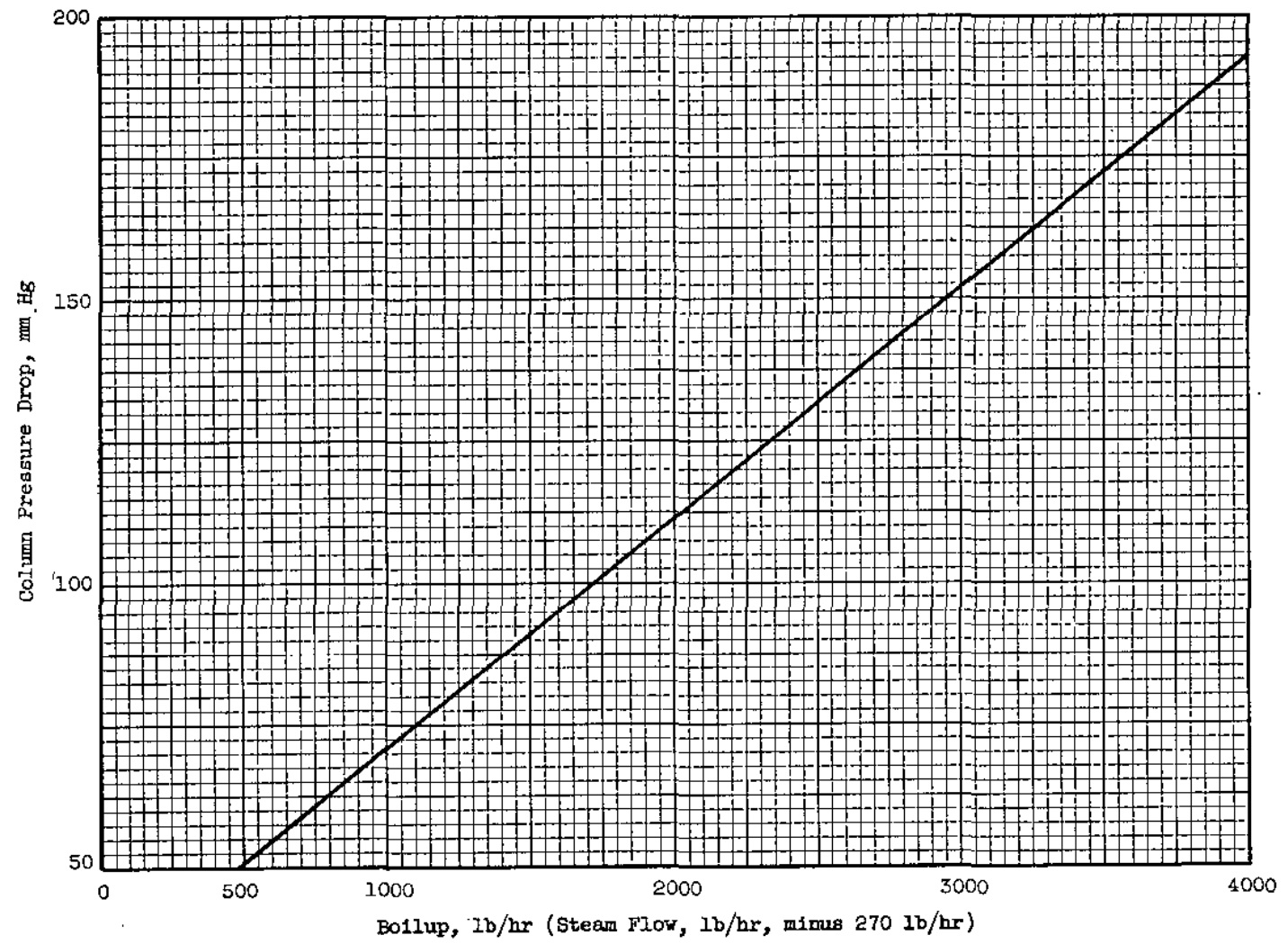

Figure 6. Boilup Rate vs Pressure Drop

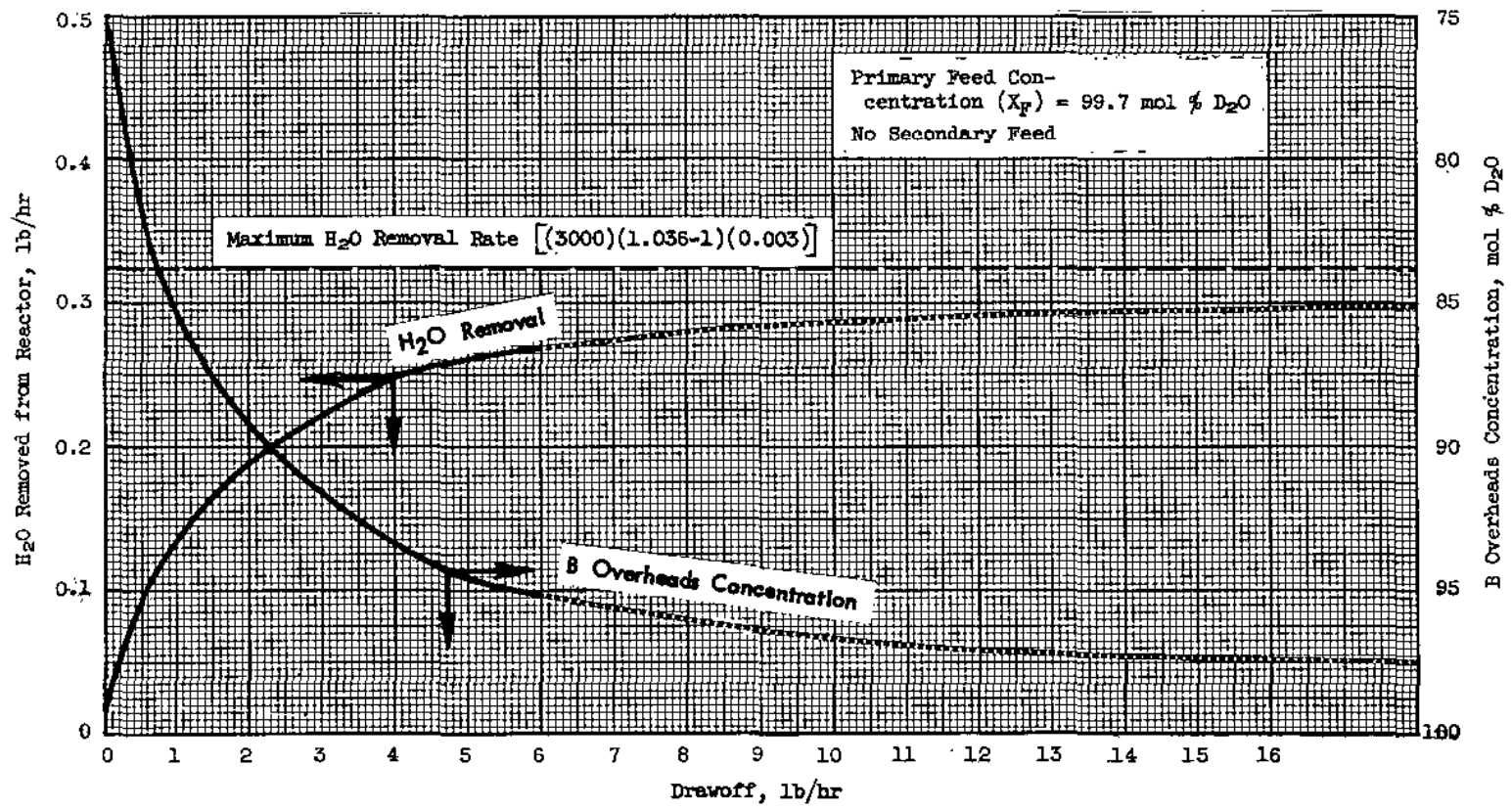

Figure 7. Drawoff Rate vs $\mathrm{H}_{2} \mathrm{O}$ Production and $\mathrm{B}$ Overheads Concentration 


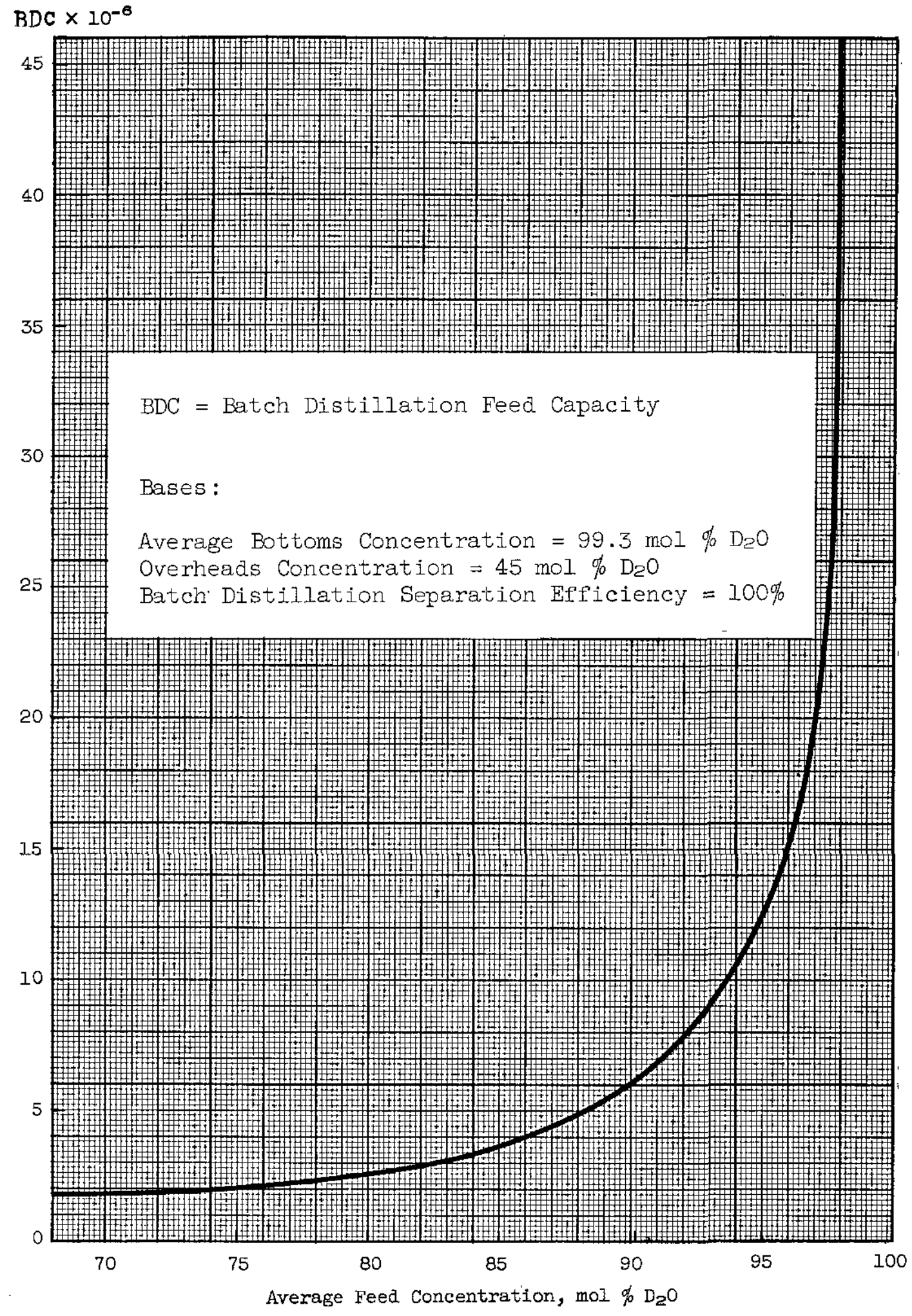

Figure 8. Batch Distillation Feed Capacity vs Feed Concentration 


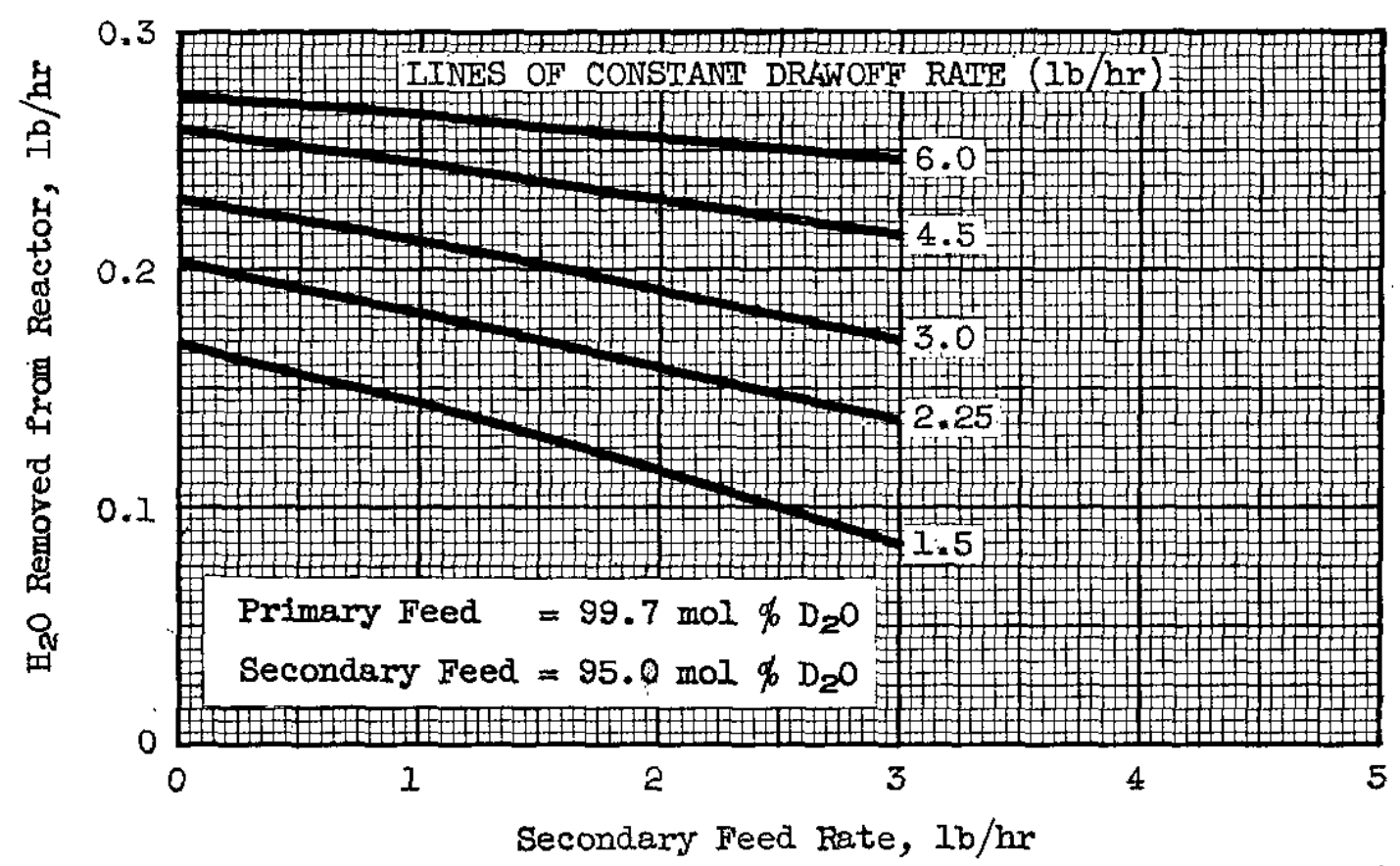

Figure 9. Secondary Feed Rate vs $\mathrm{H}_{2} \mathrm{O}$ Production Rate at Various Drawoff Rates

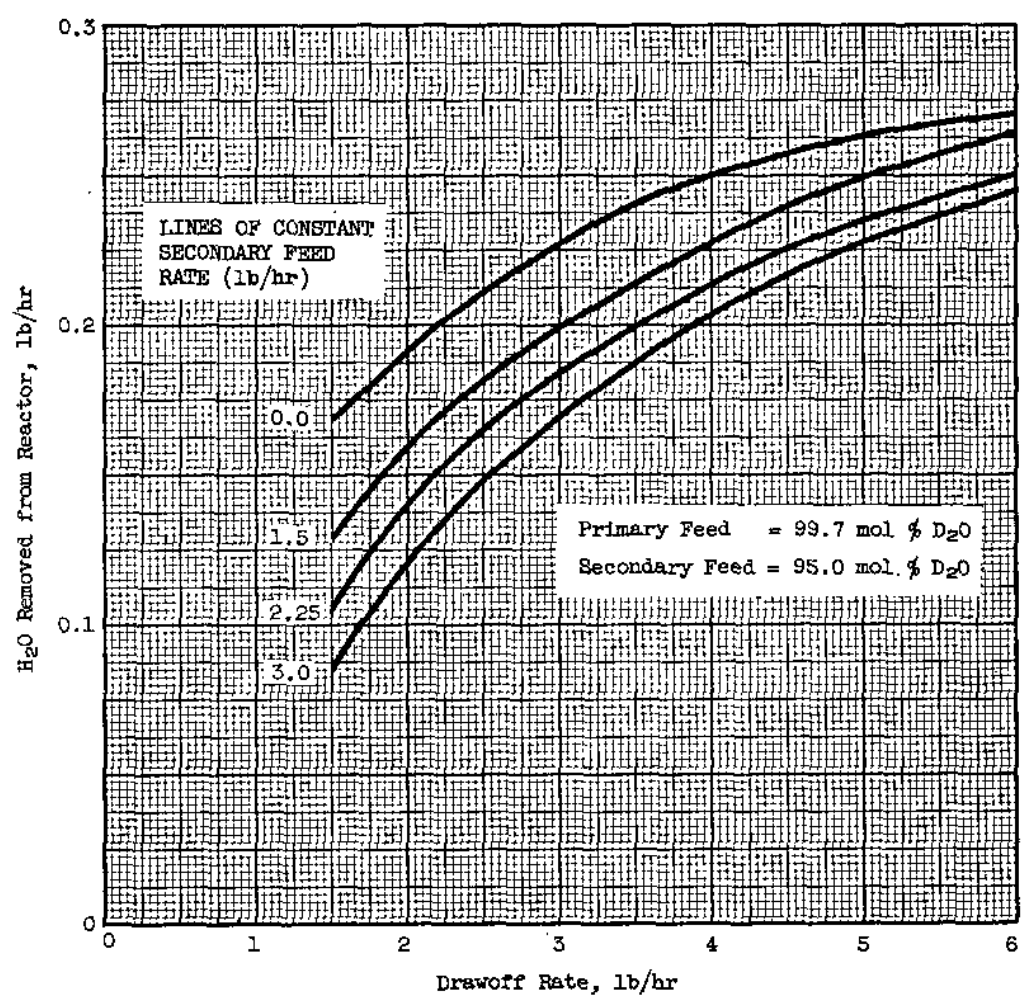

Figure 10. Drawoff Rate vs $\mathrm{H}_{2} \mathrm{O}$ Production Rate at Various Secondary Feed Rates 


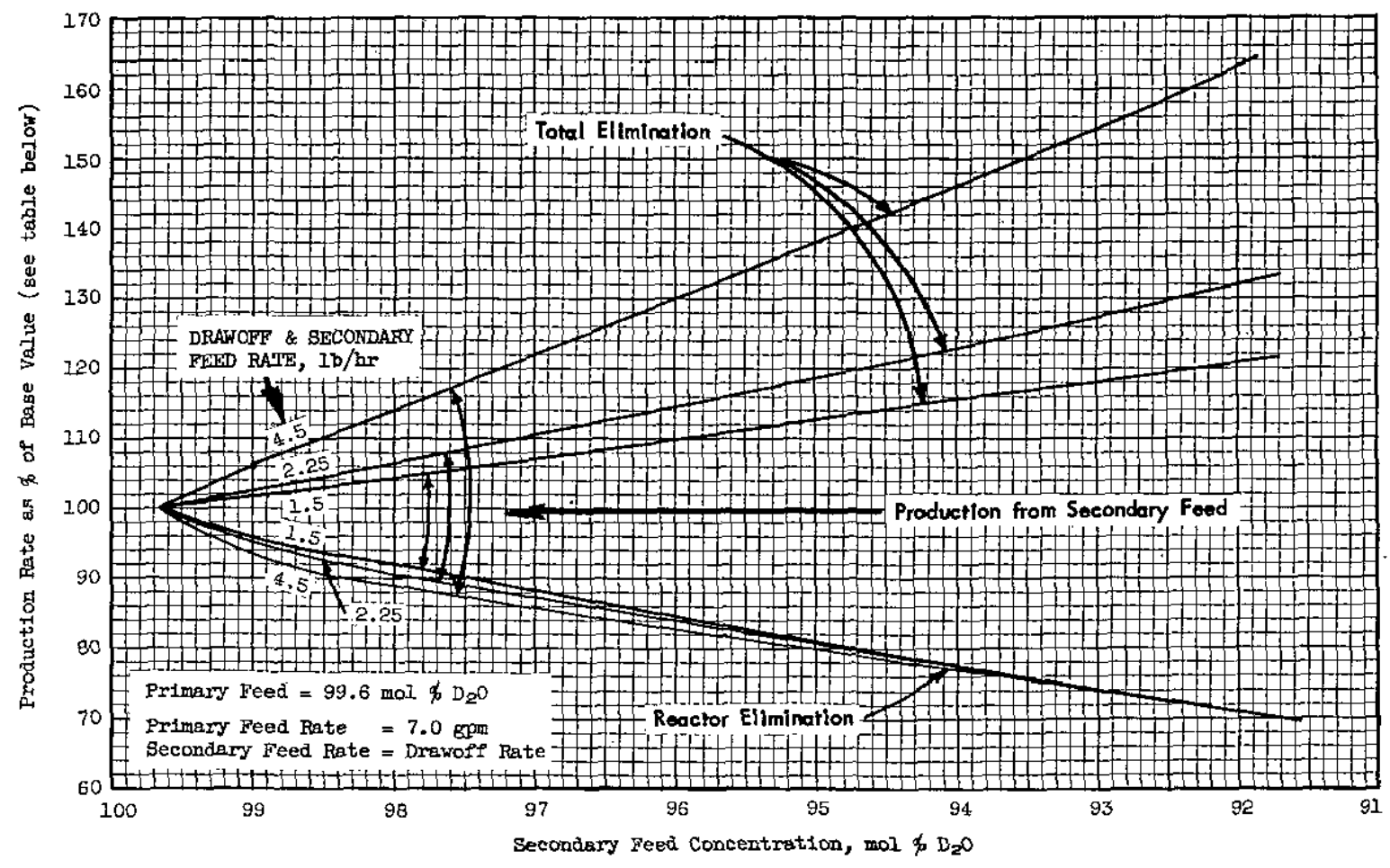

Figure II. Light Water Production and Elimination Rates vs Secondary Feed Concentration

Base Production with No Second-

\begin{tabular}{|c|c|}
\hline \multicolumn{2}{|c|}{ ary Feed (100\% vilue) } \\
\hline $\begin{array}{c}\text { Drawoff Rate, } \\
\text { Ib/hr }\end{array}$ & $\begin{array}{l}\mathrm{H}_{2} \mathrm{O} \text { Production, } \\
\mathrm{lb} / \mathrm{hr}\end{array}$ \\
\hline 1.5 & 0.218 \\
\hline 2.25 & 0.266 \\
\hline 4.5 & 0.342 \\
\hline
\end{tabular}

(from calculations made

by S. M. Katz, SRL) 


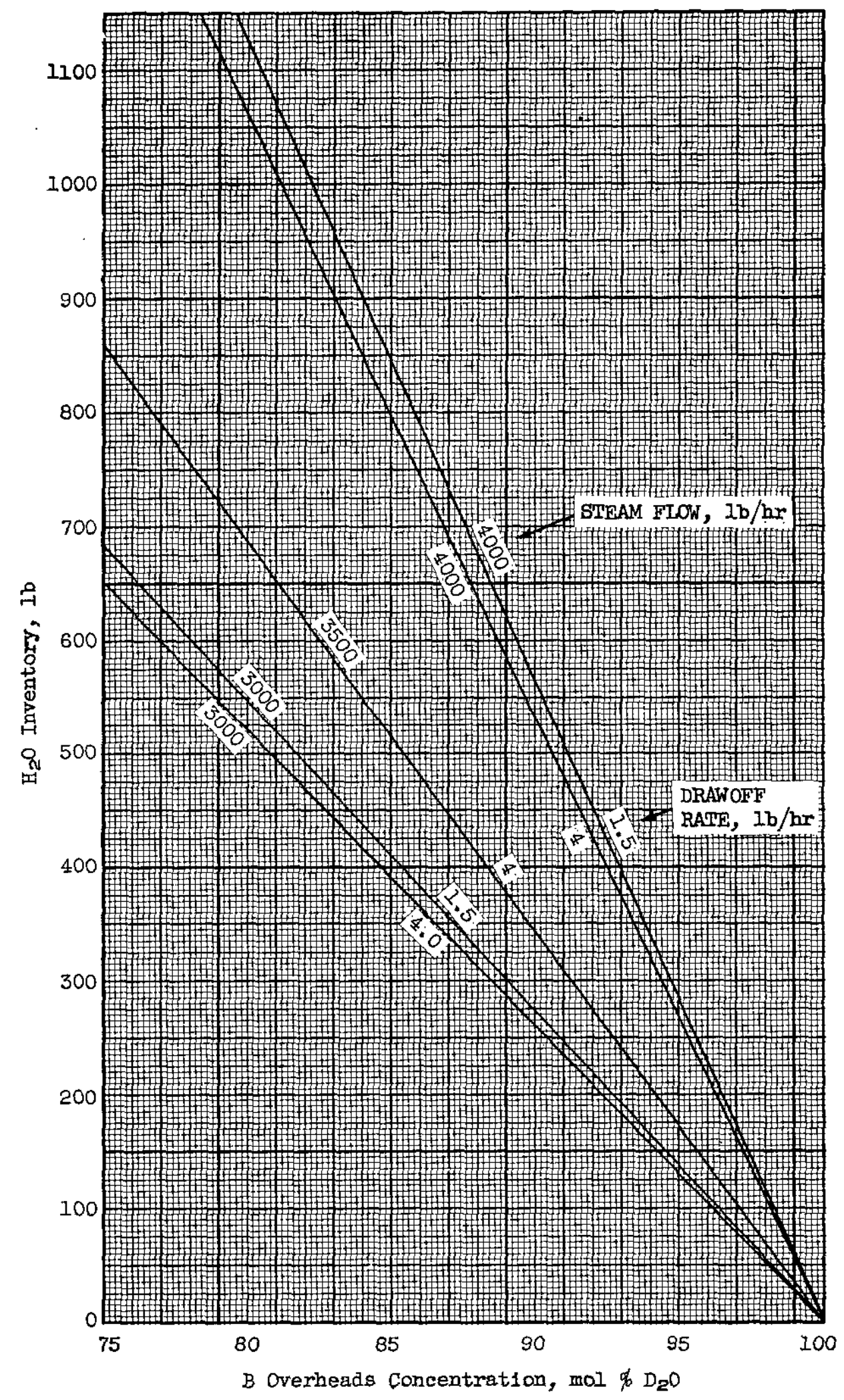

Figure 12. $\mathrm{H}_{2} \mathrm{O}$ Inventory vs $\mathrm{B}$ Overheads Concentration at Various Steam Flows and Drawoff Rates 


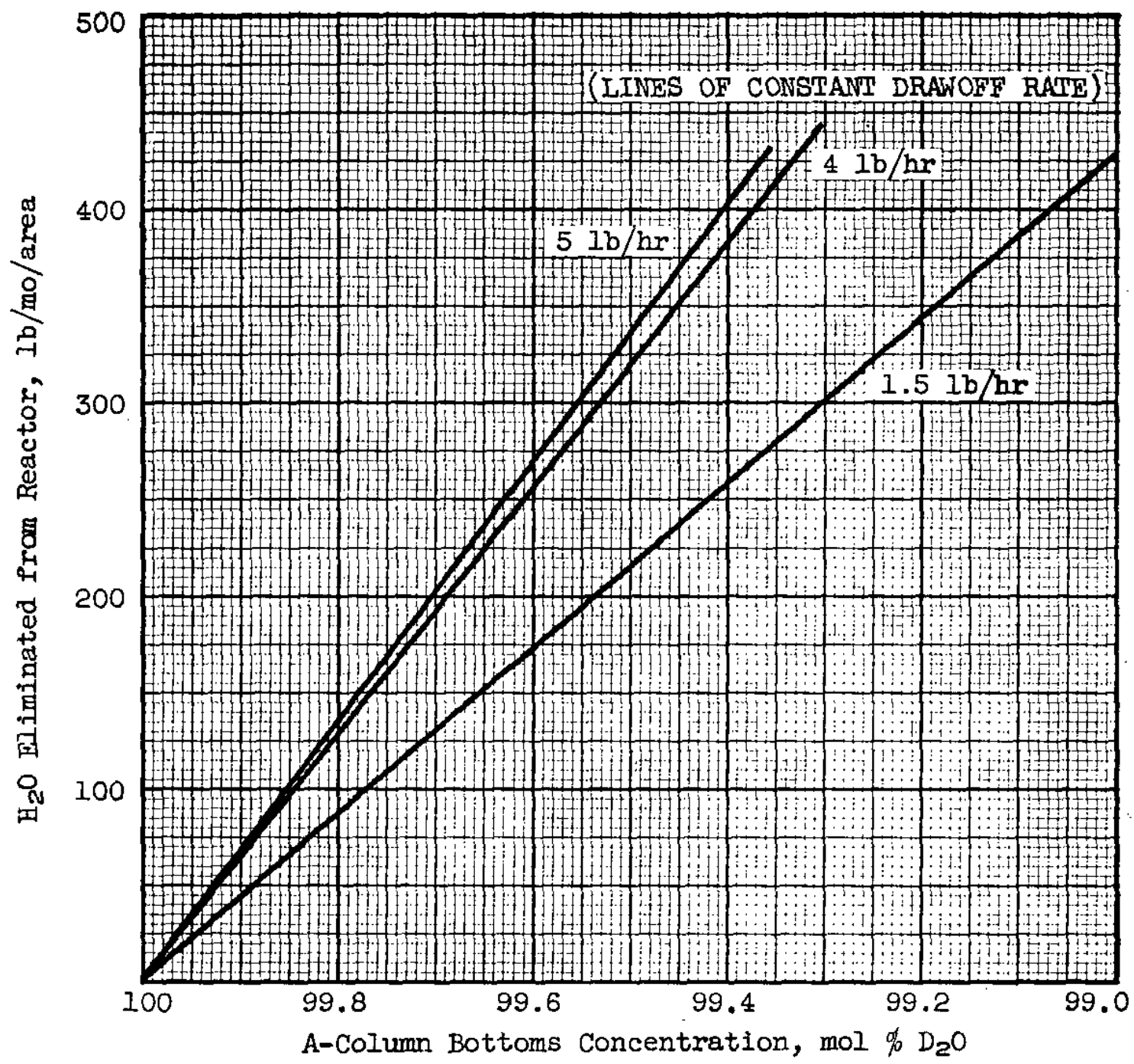

Figure 13. Standard Light Water Production Rate (No Secondary Feed) 


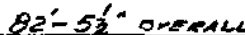

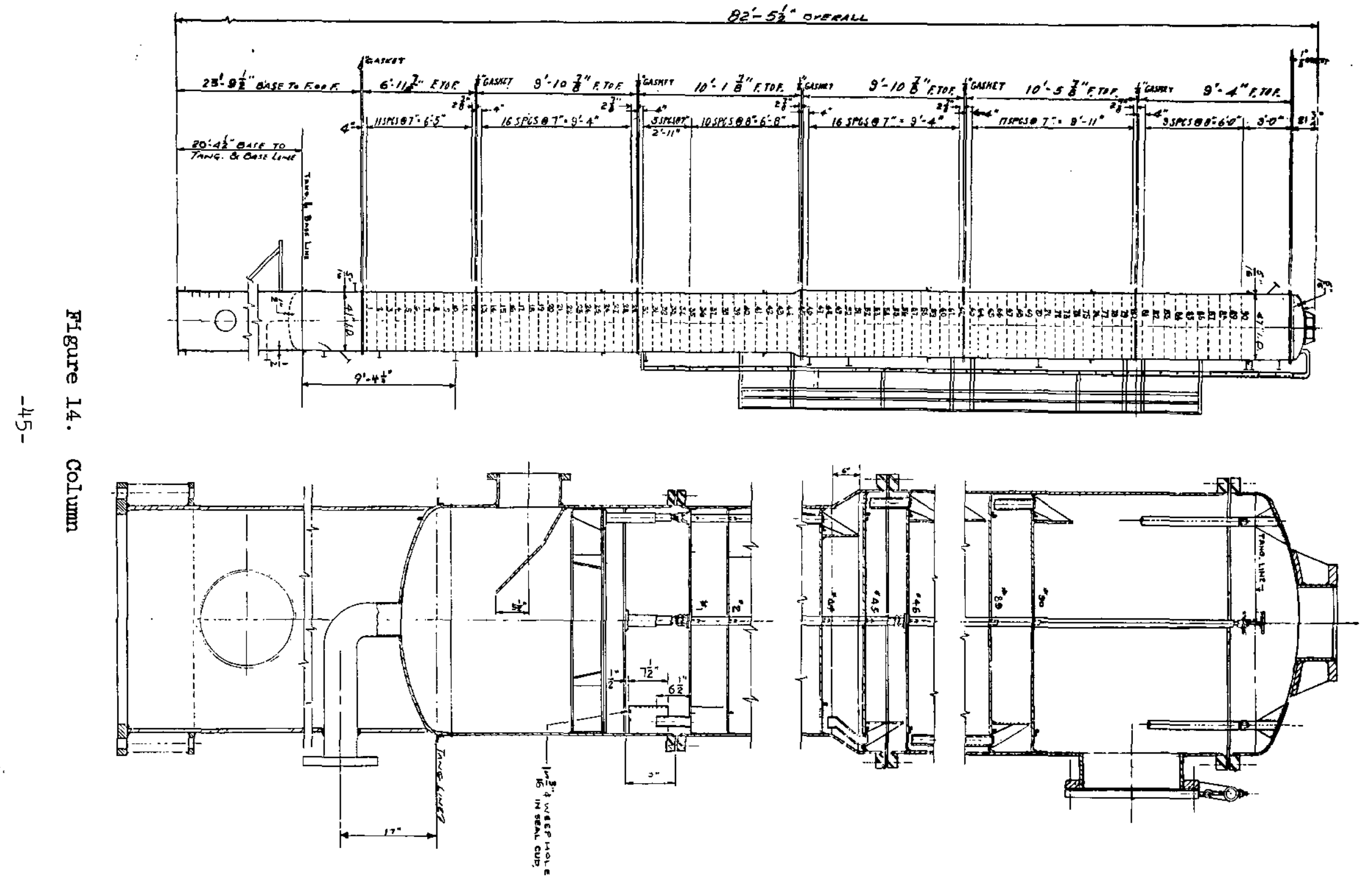




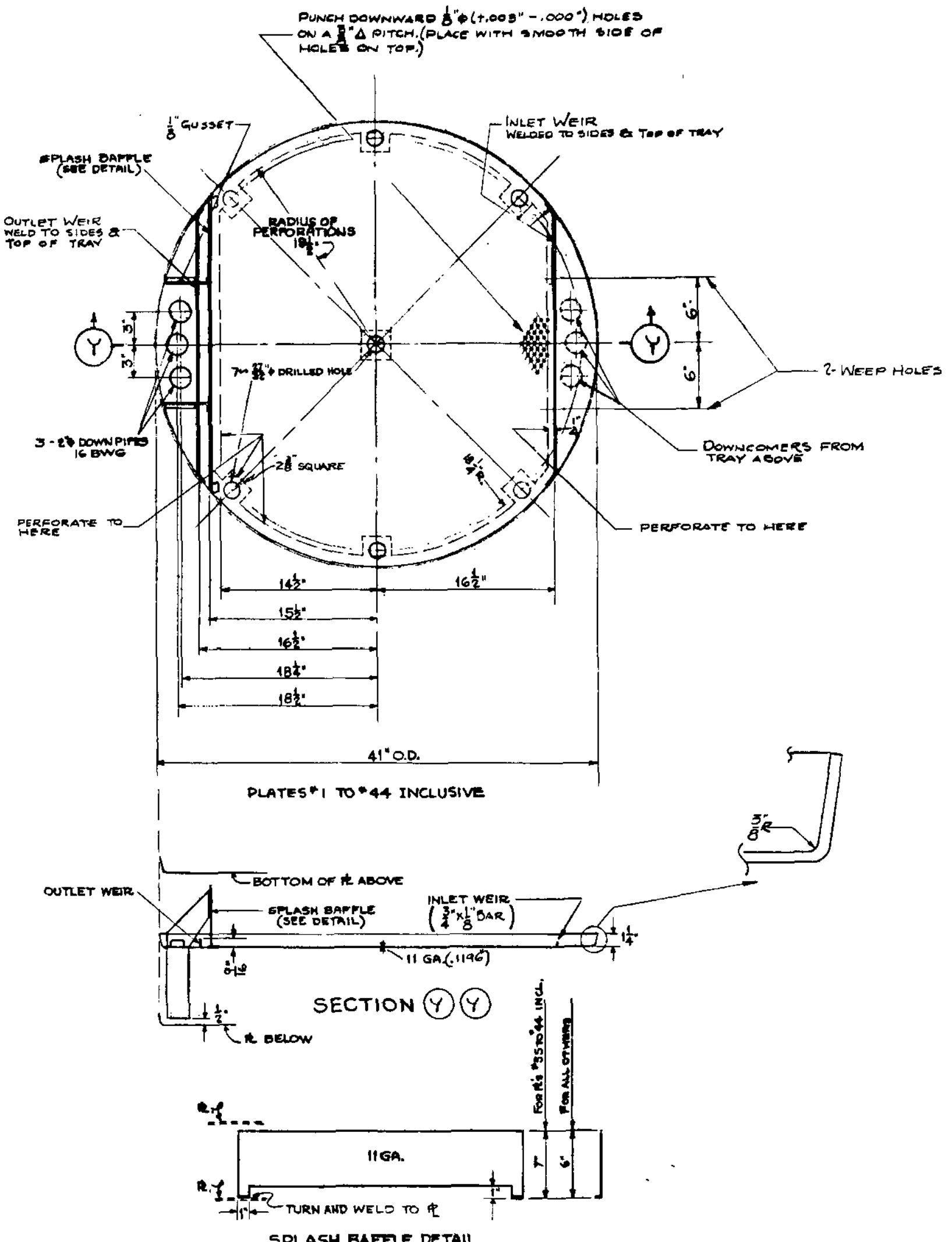

SPLASH BAFTLE DETAIL

Figure 15. Sieve Plate 

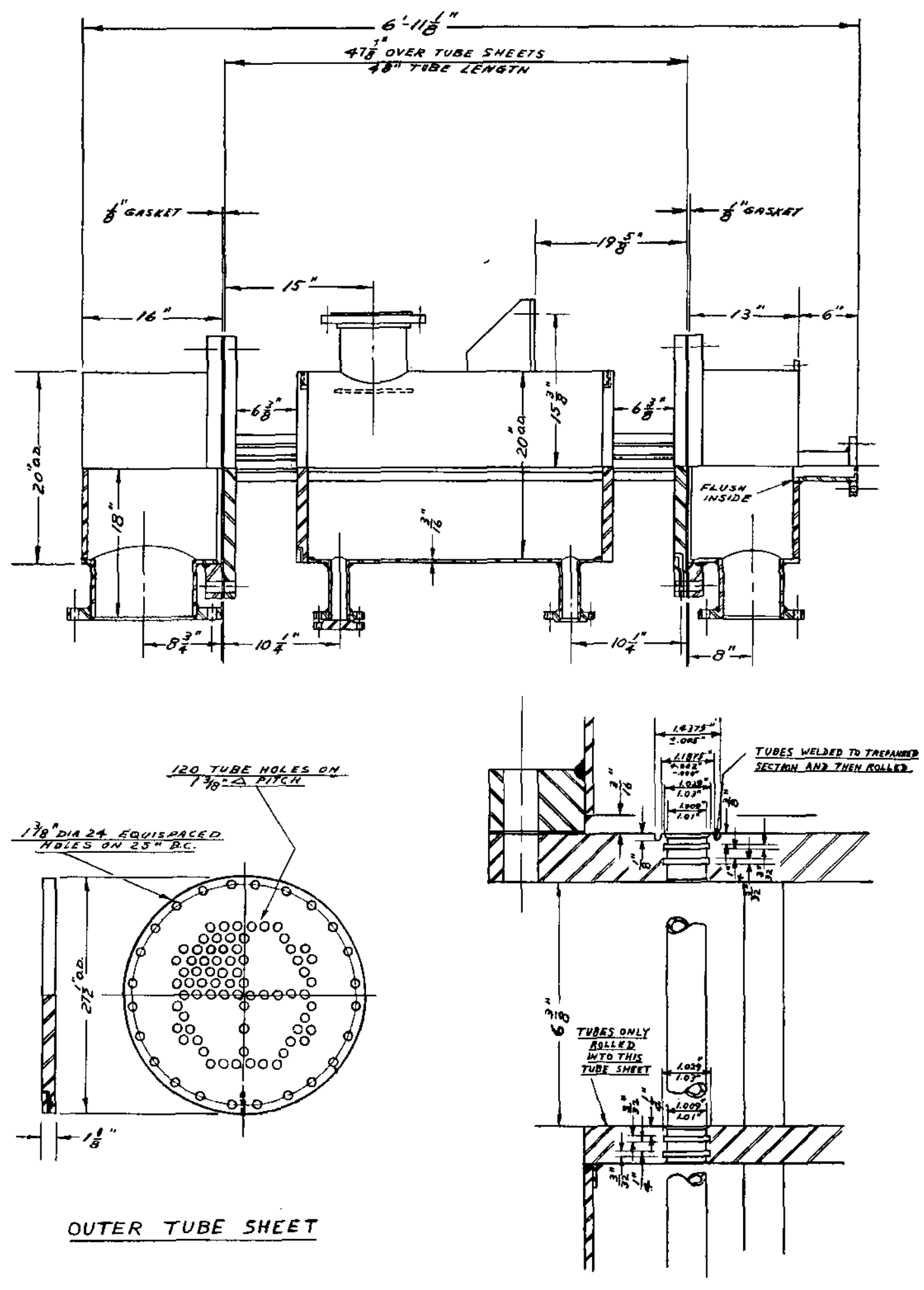

DOUBLE TUBE SHEET DETAILS

Figure 16. Reboiler 

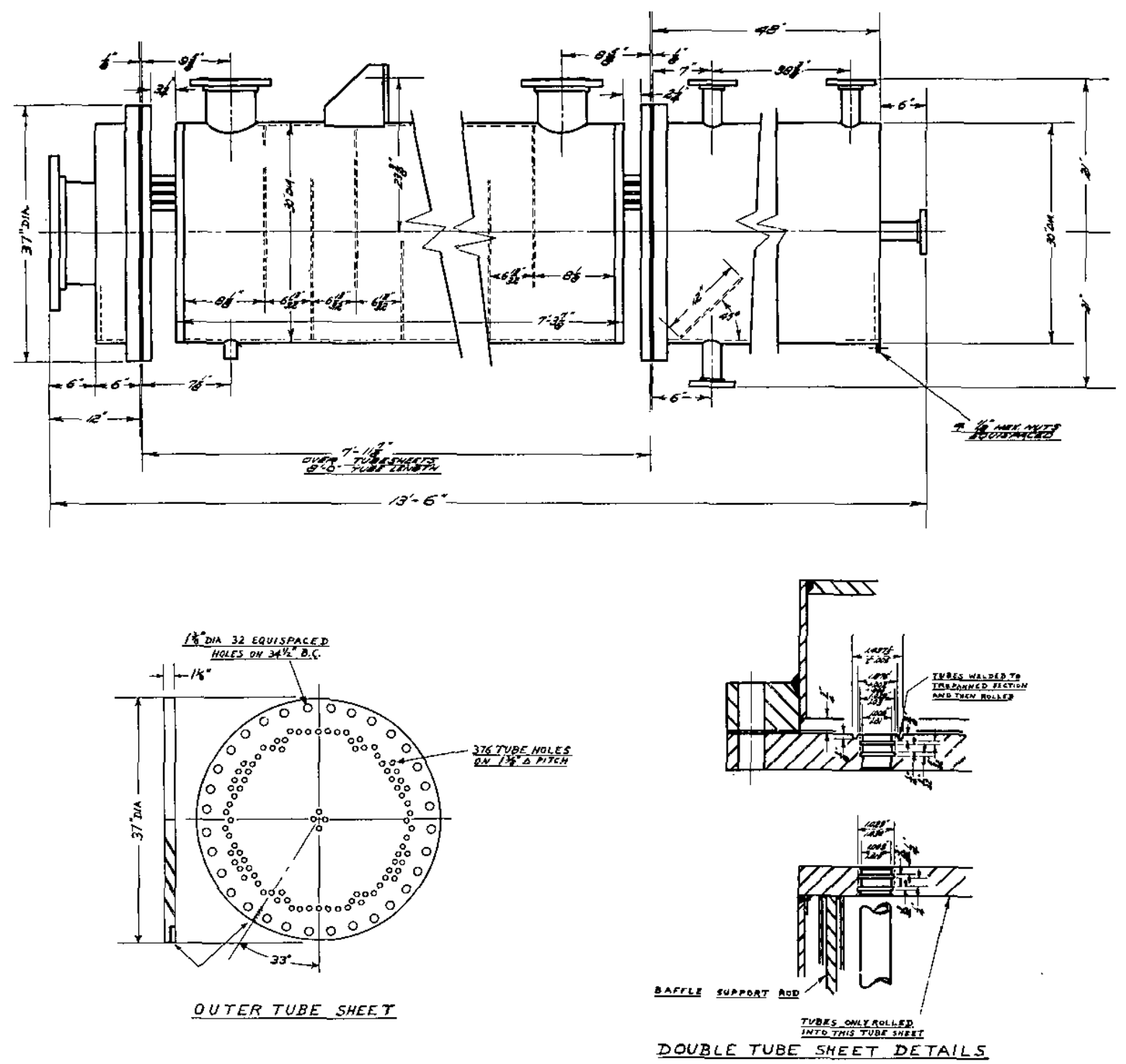

Figure 17. Column Condenser 
6
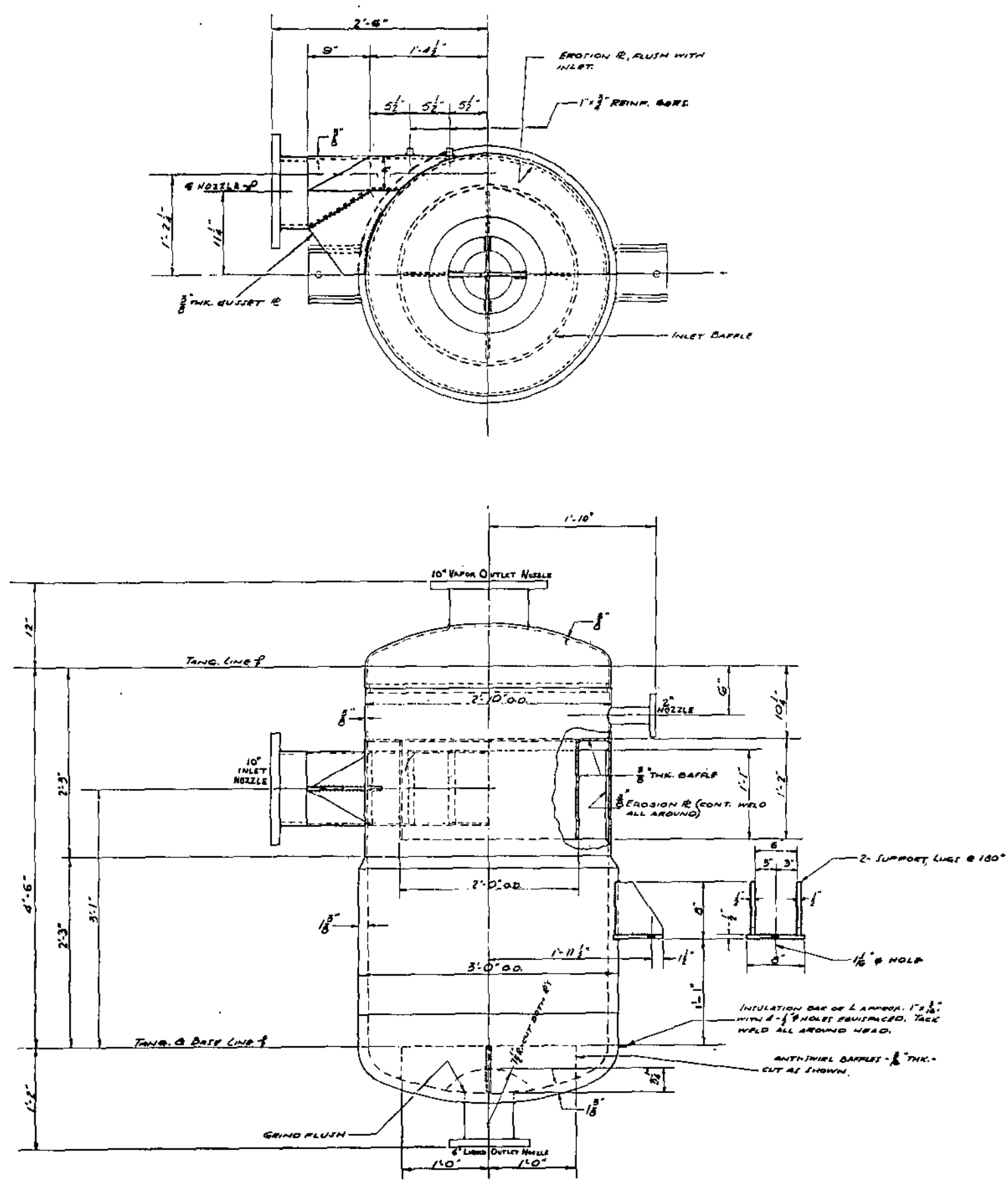

Figure 18. Reboiler Separator 


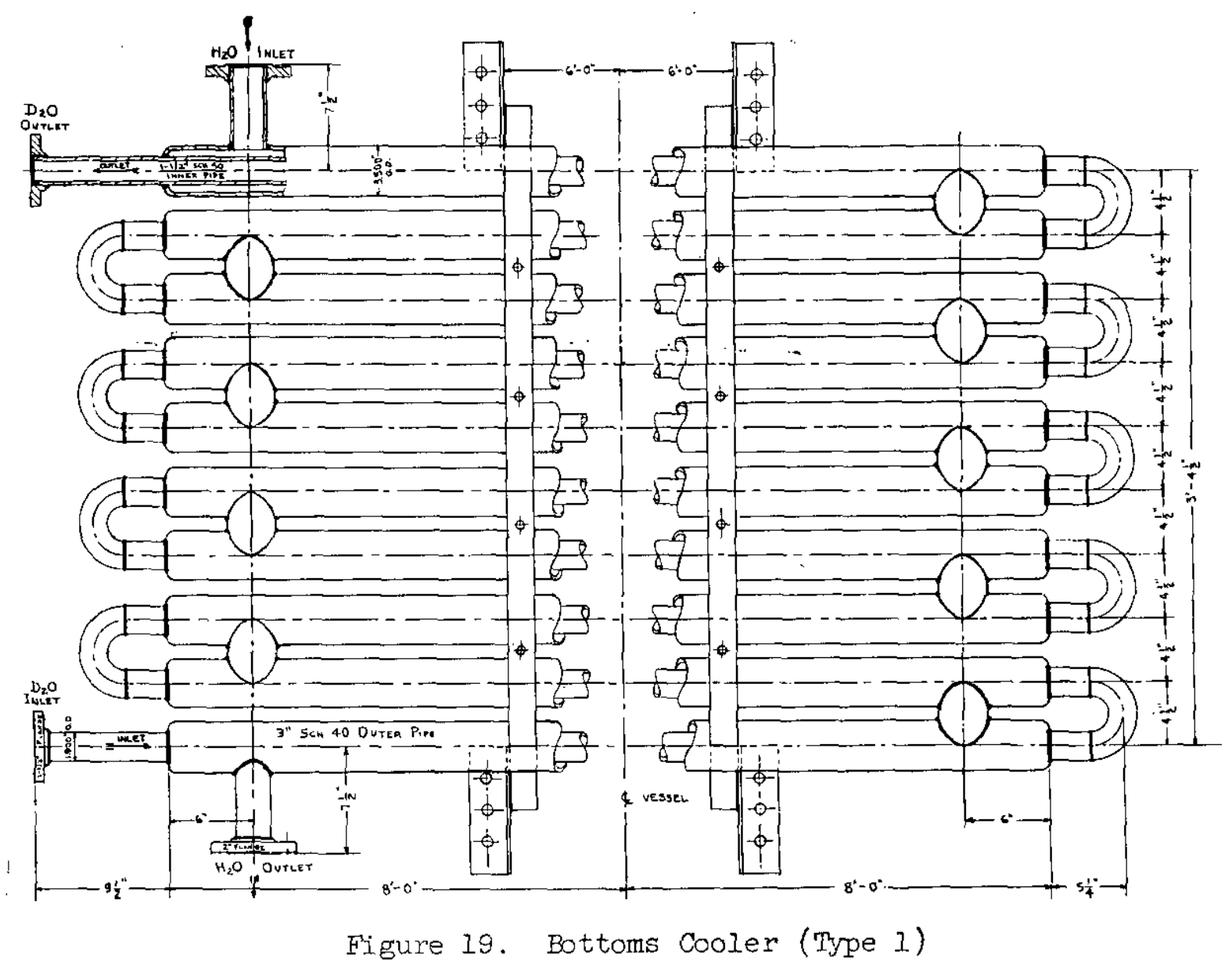



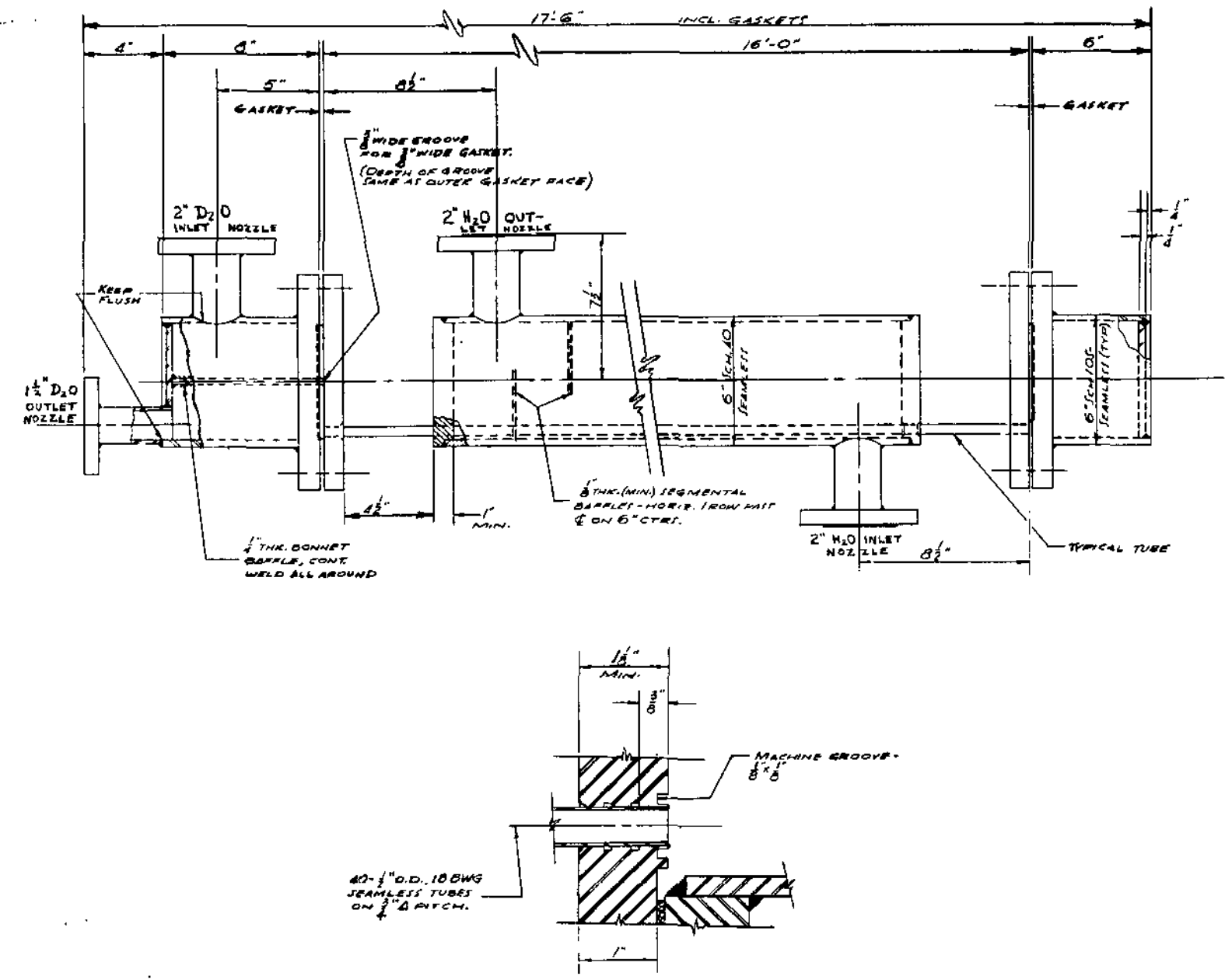

Outea Tube sheet Detailh

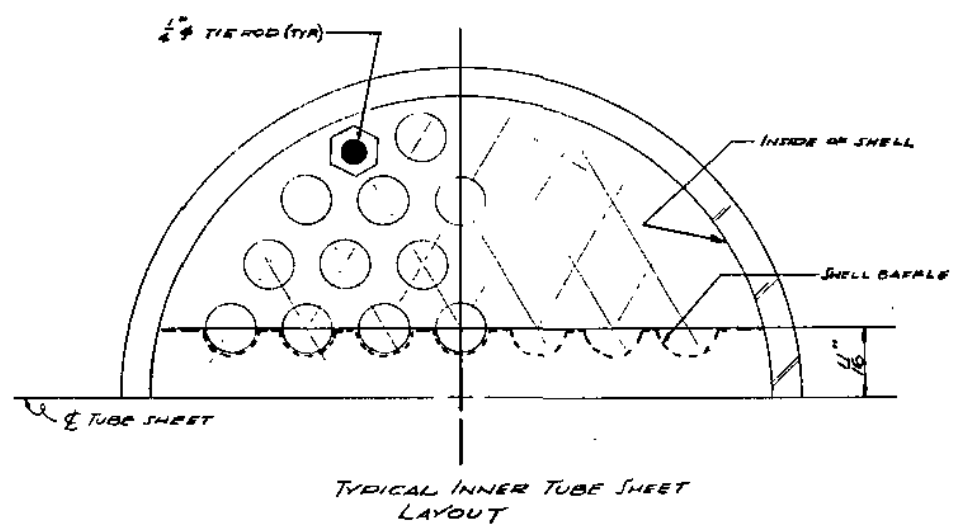

Figure 20. Bottoms Cooler (Type 2) 

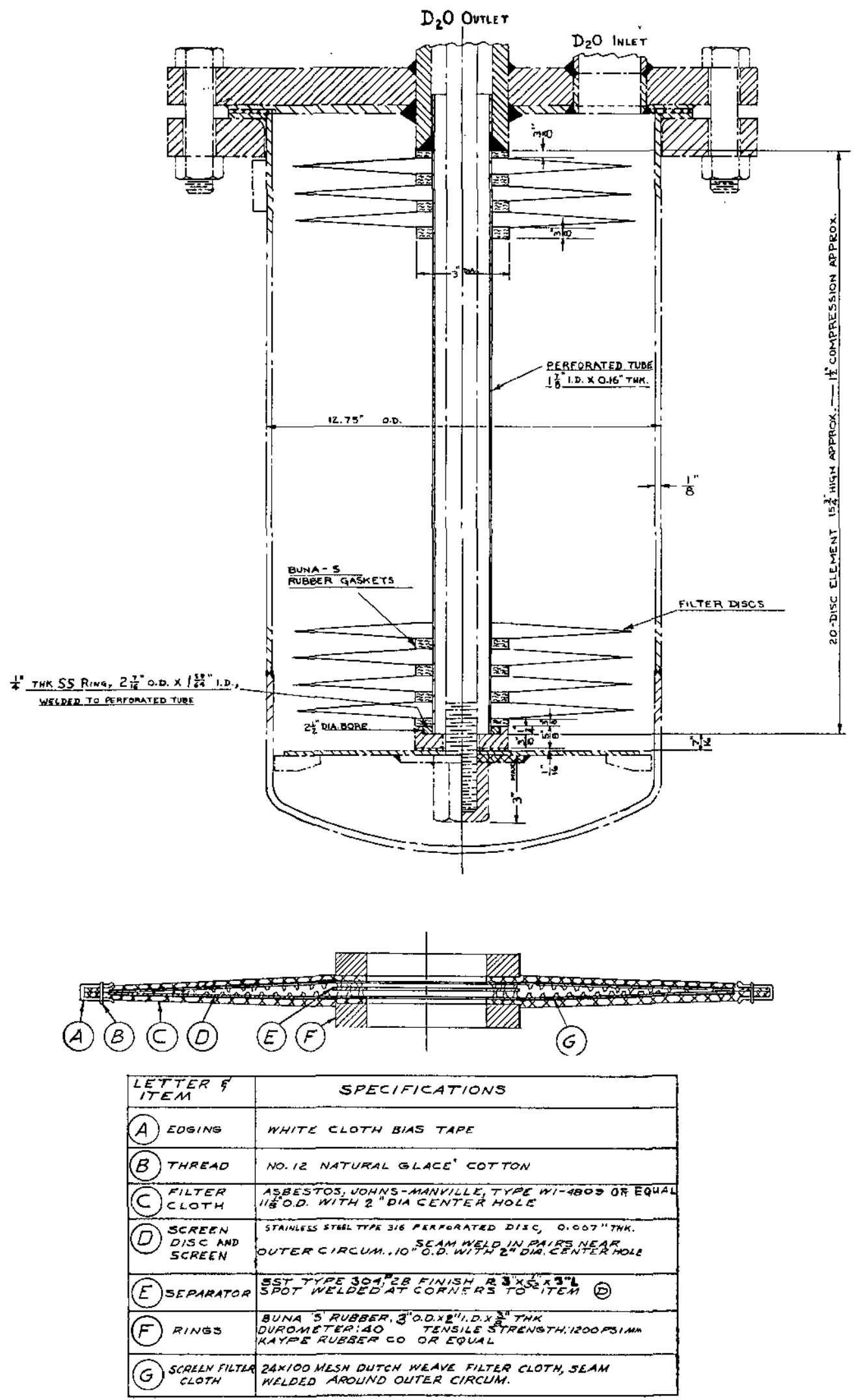

\section{FILTER ELEMENT}

Figure 21. Bottoms Filter 


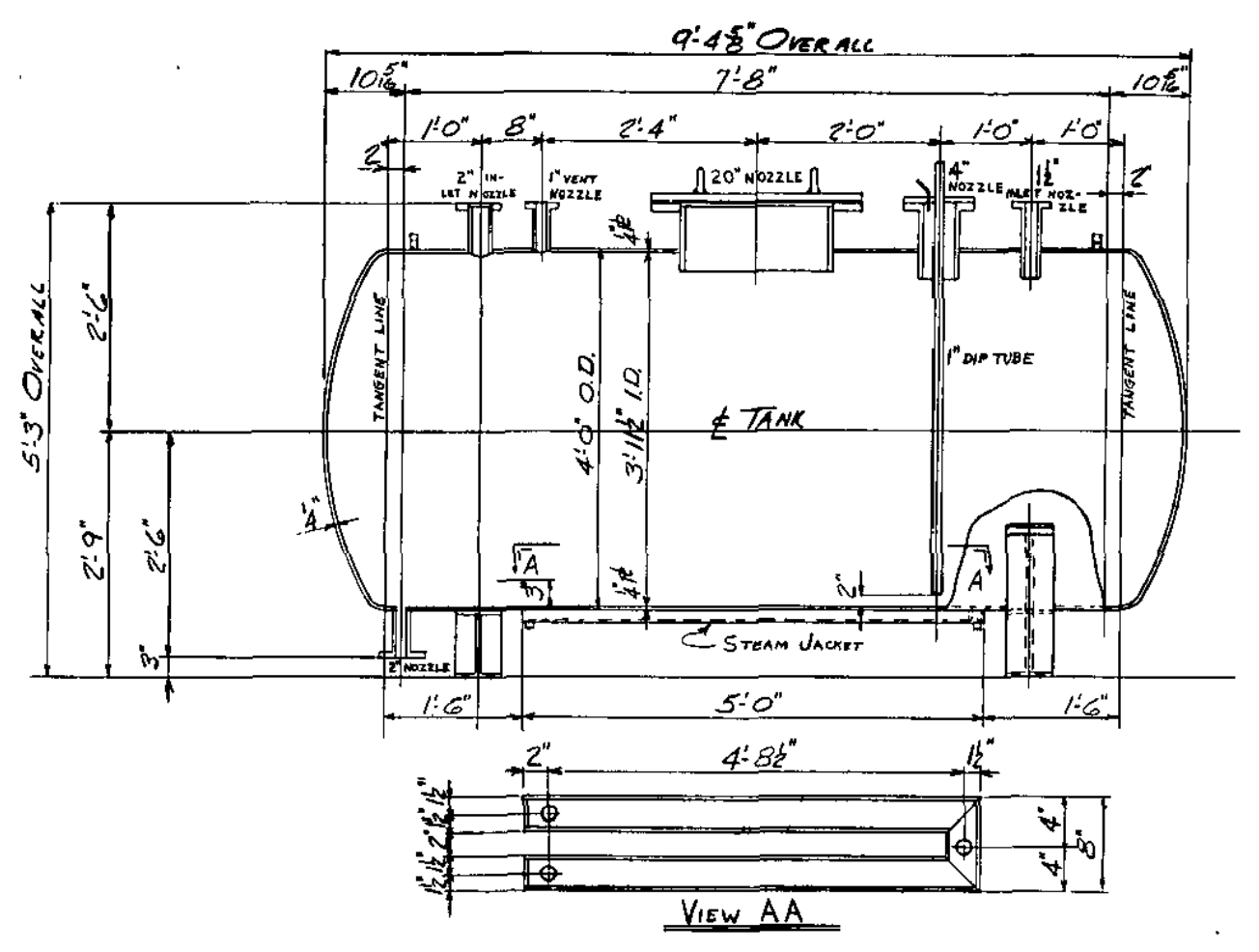

Figure 22. Rundown Tank

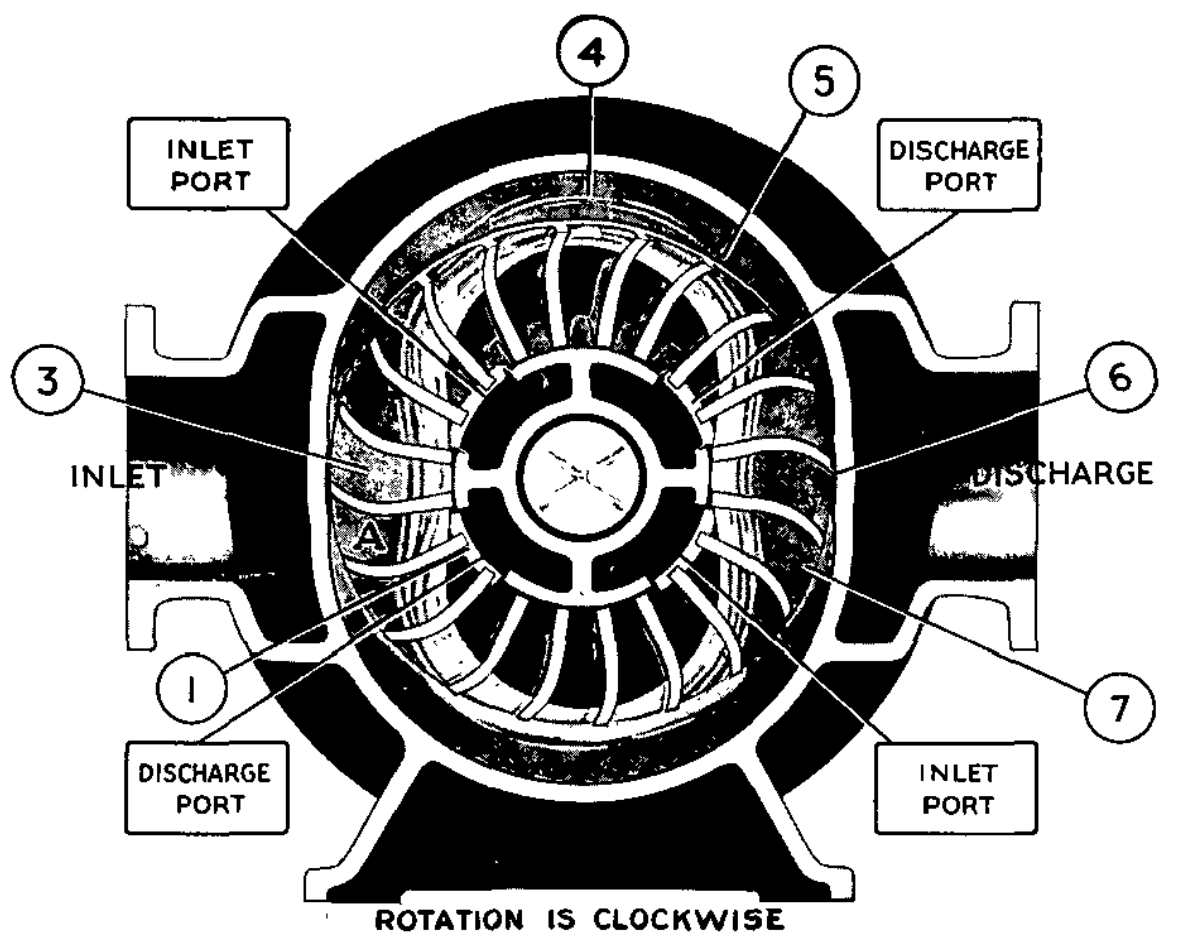

Figure 23. Vacuum Prump 


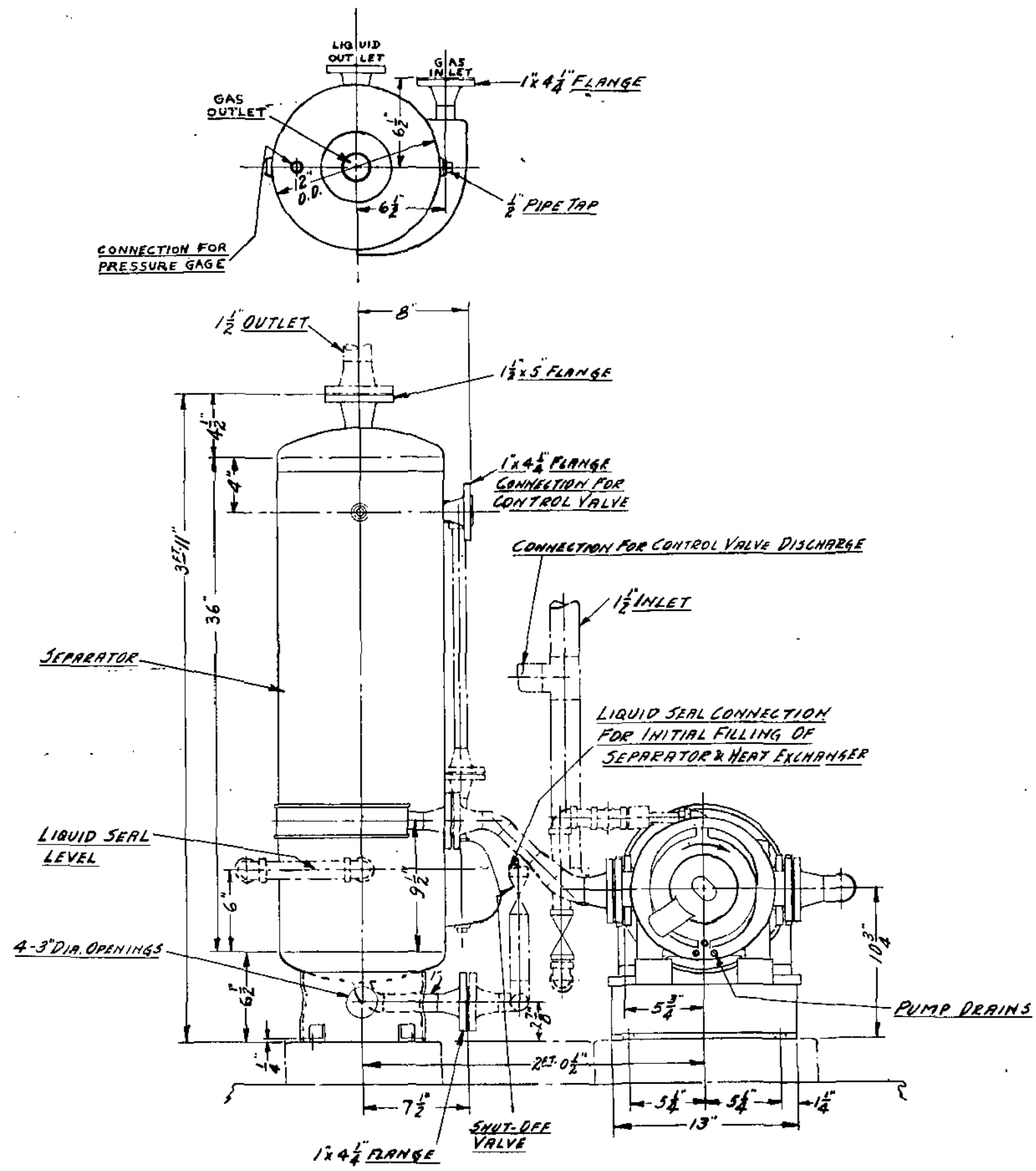

Figure 24. Vacuum Pump Separator 


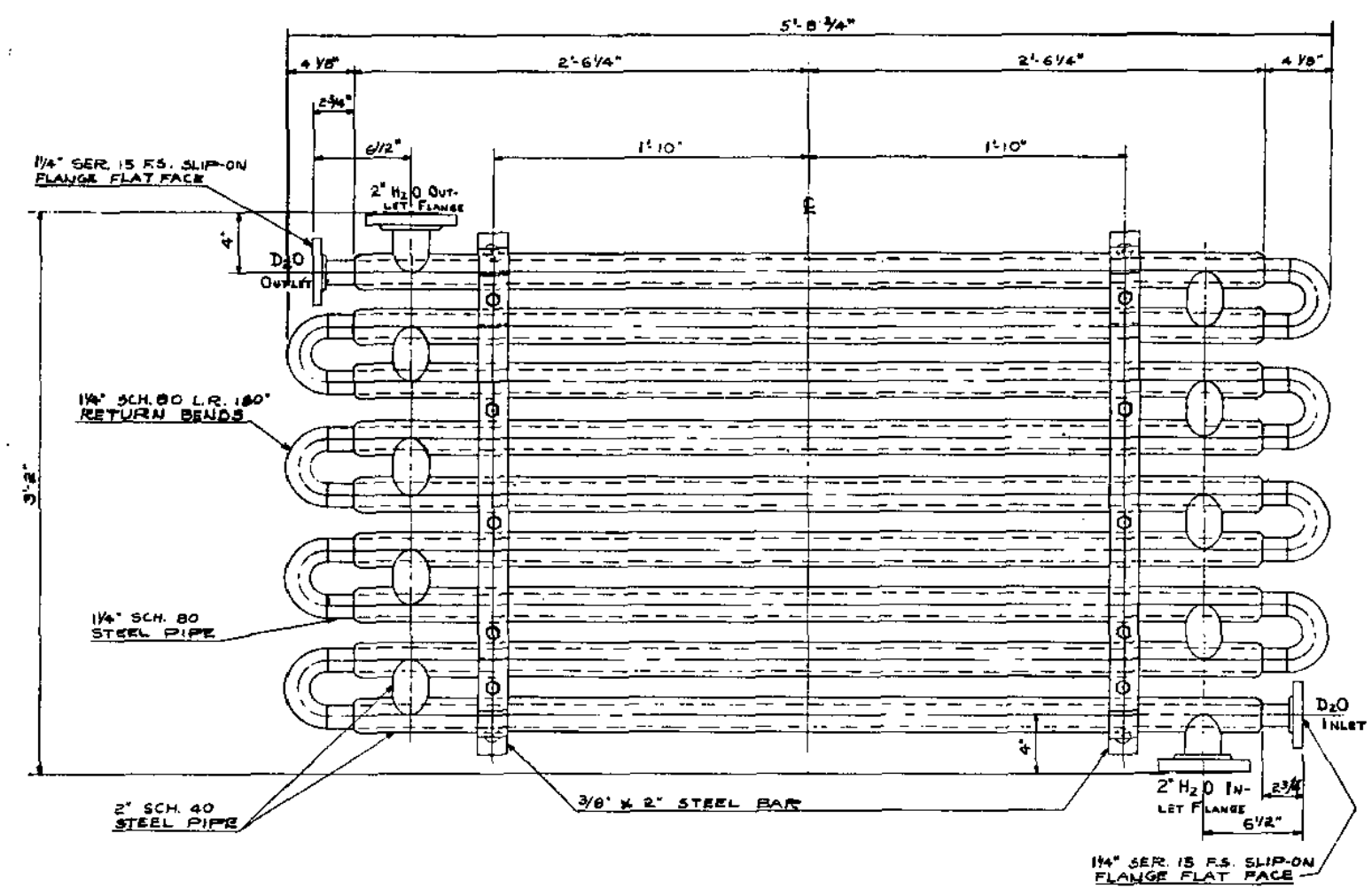

Figure 25. Vacuum Pump Cooler 

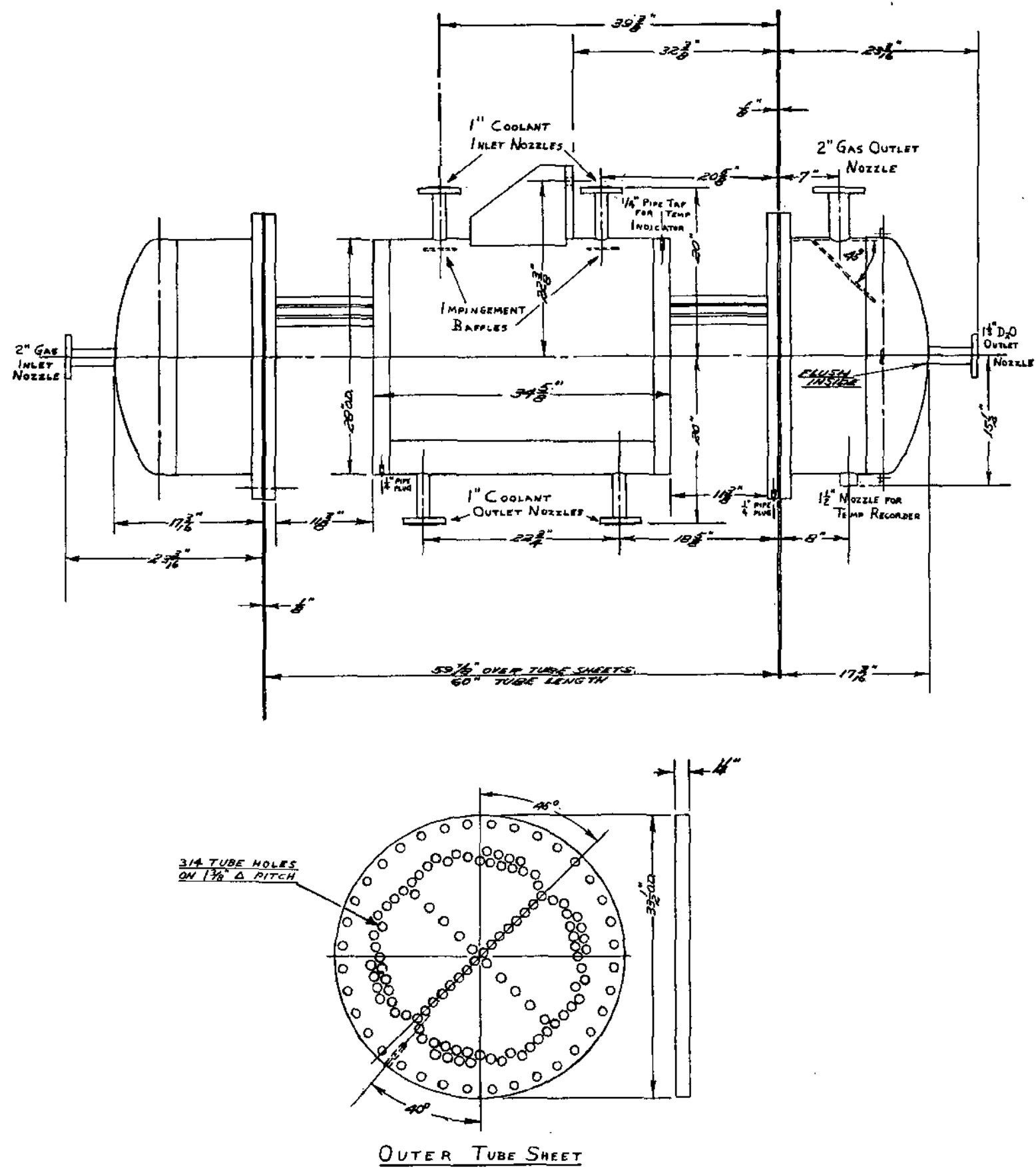

Figure 26. Vent Condenser (Type 1) 

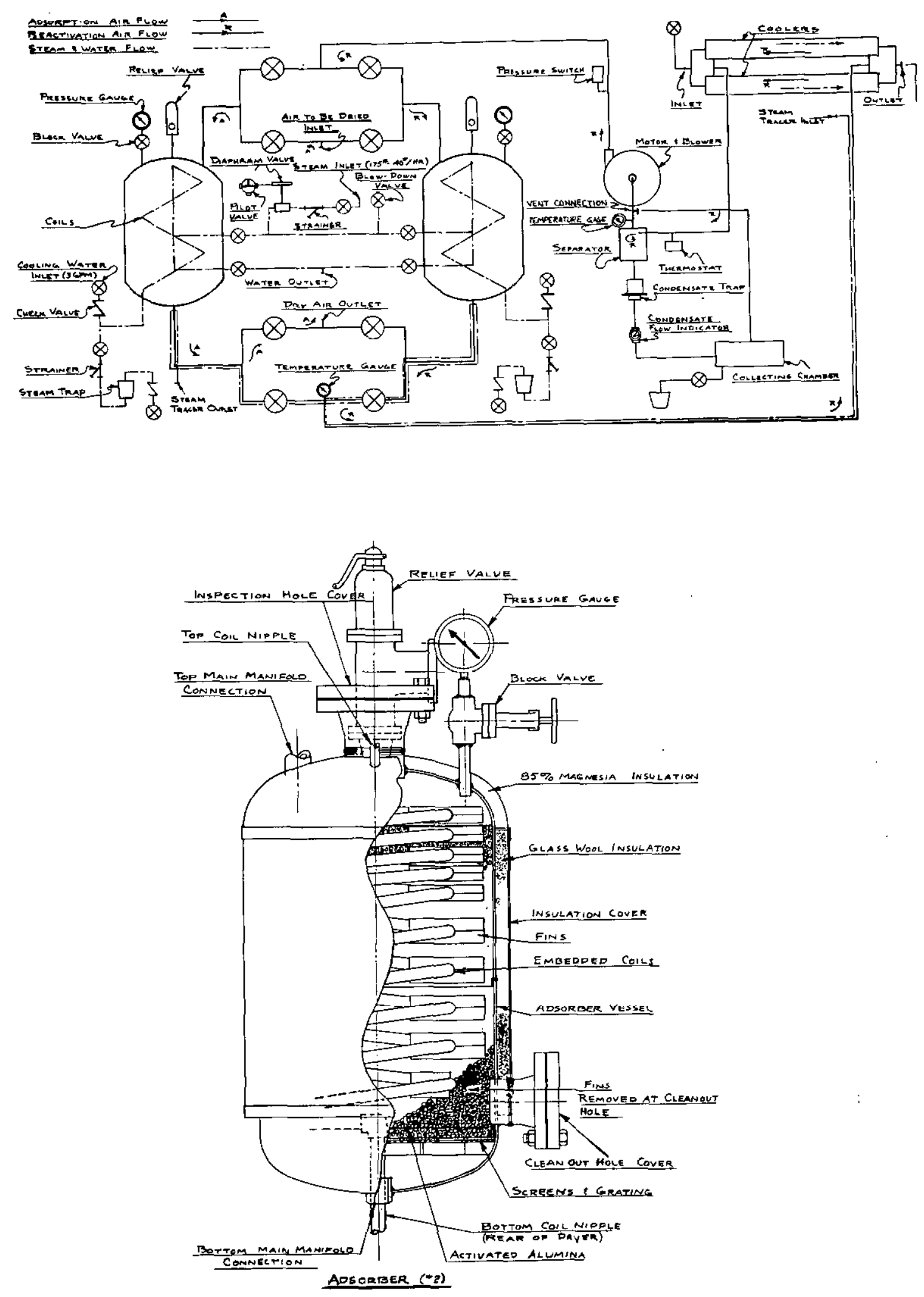

Figure 27. Vent Gas Dryer (Type 2) 


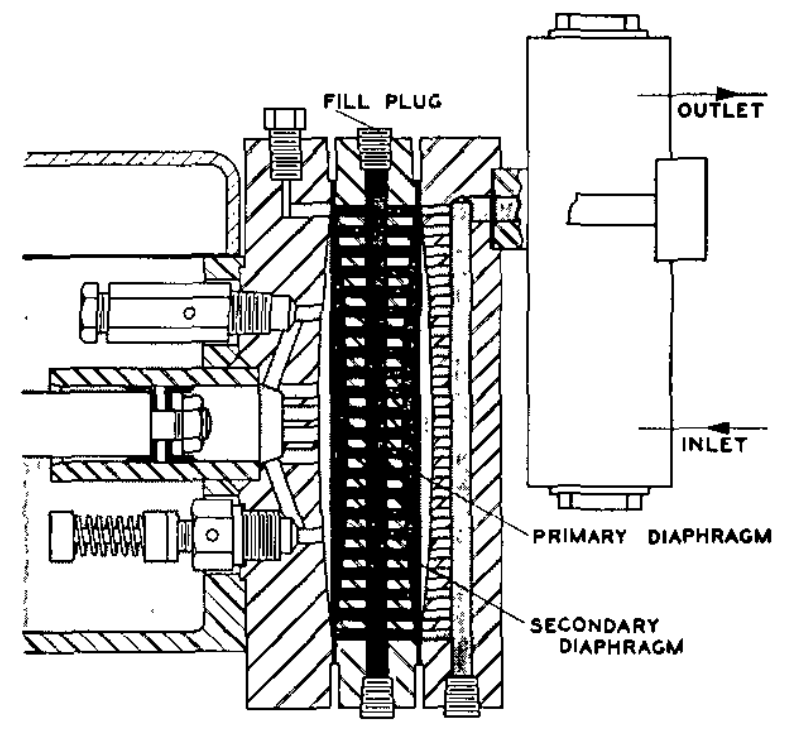

Figure 28. Metering Pump

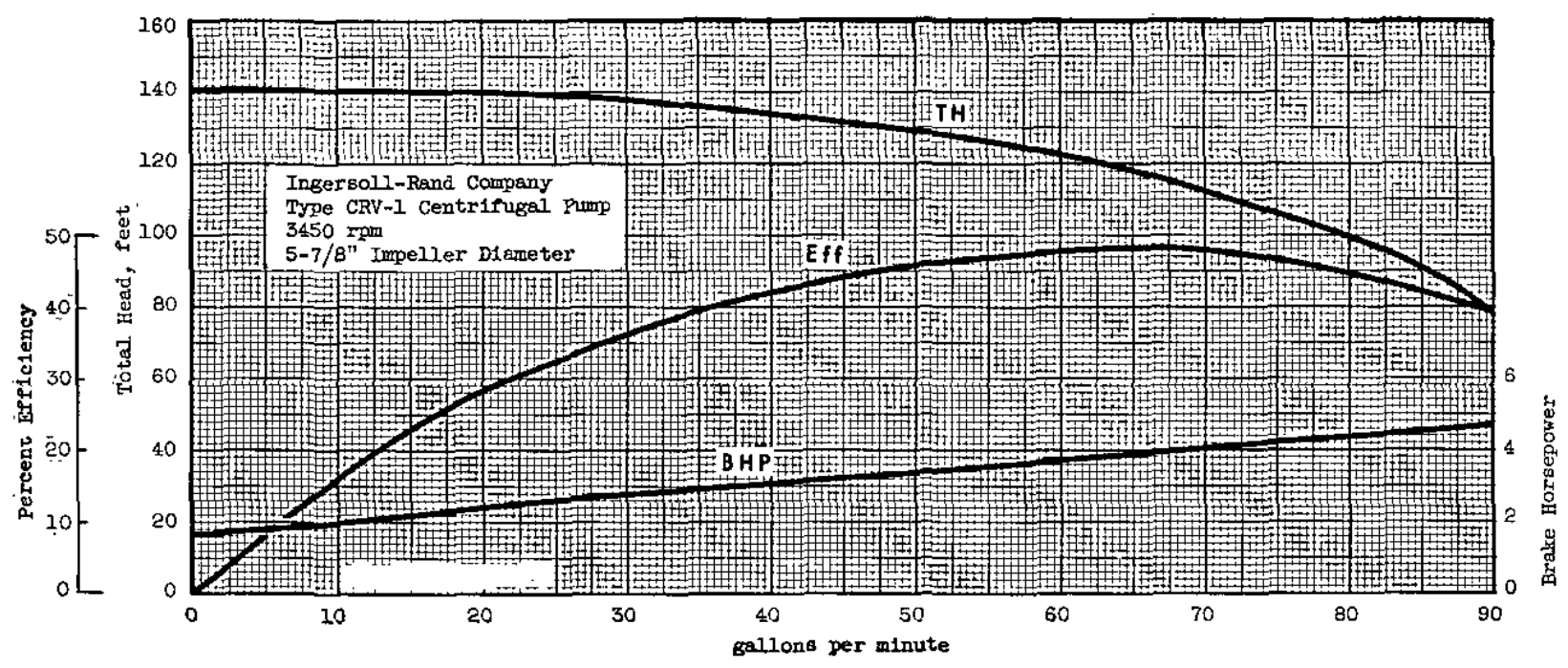

Figure 29. Centrifugal Pump Characteristic Curves 


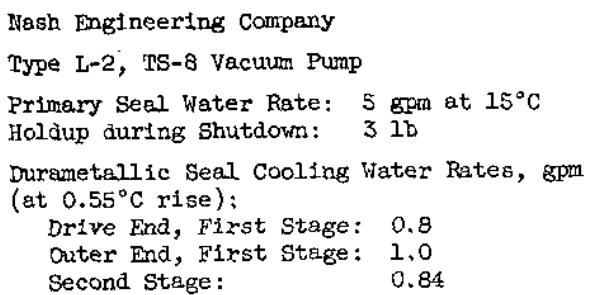

Figure 30. Vacuum Pump Characteristic Curves

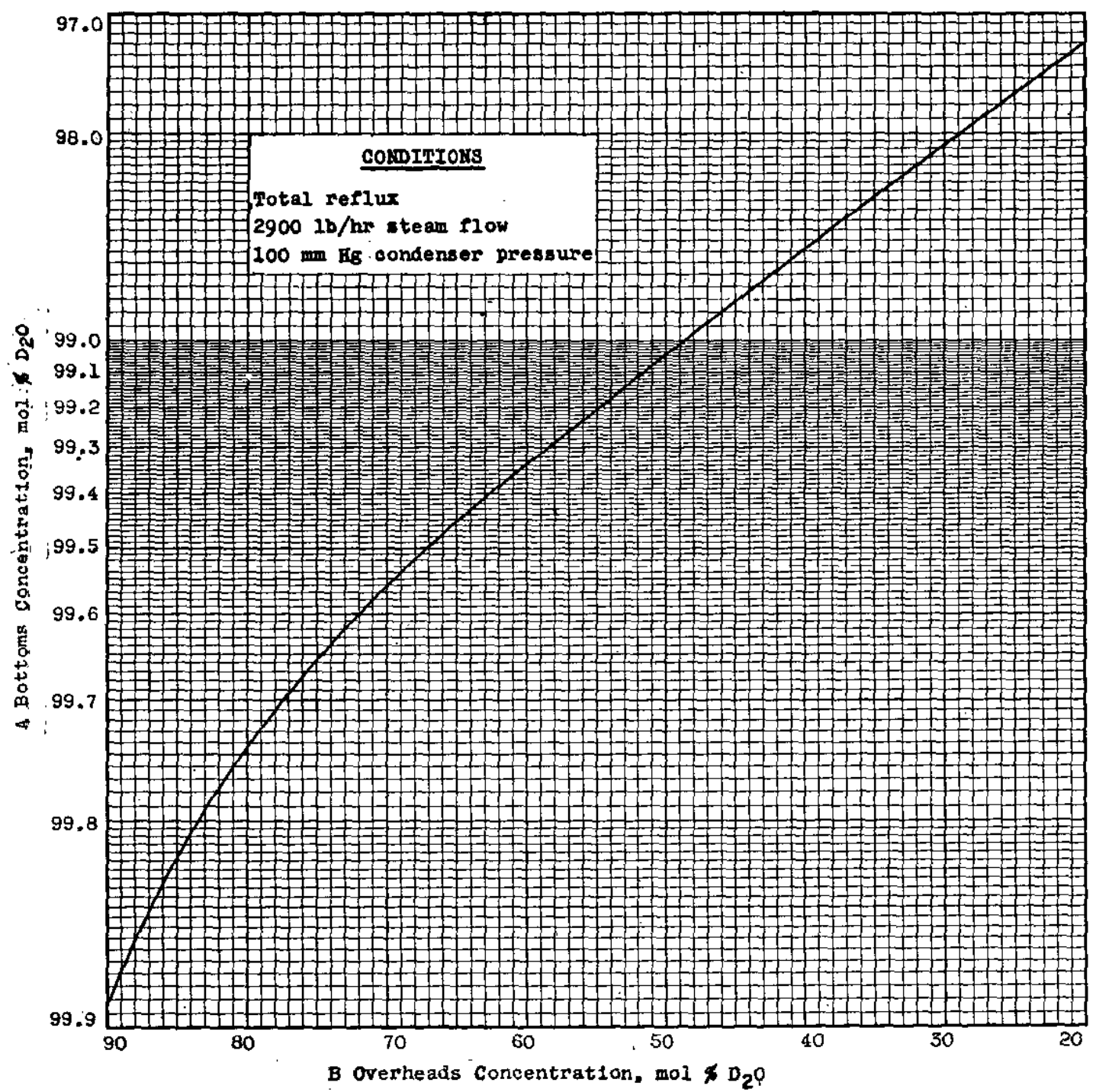

Figure 31. Distillation System Concentrations 


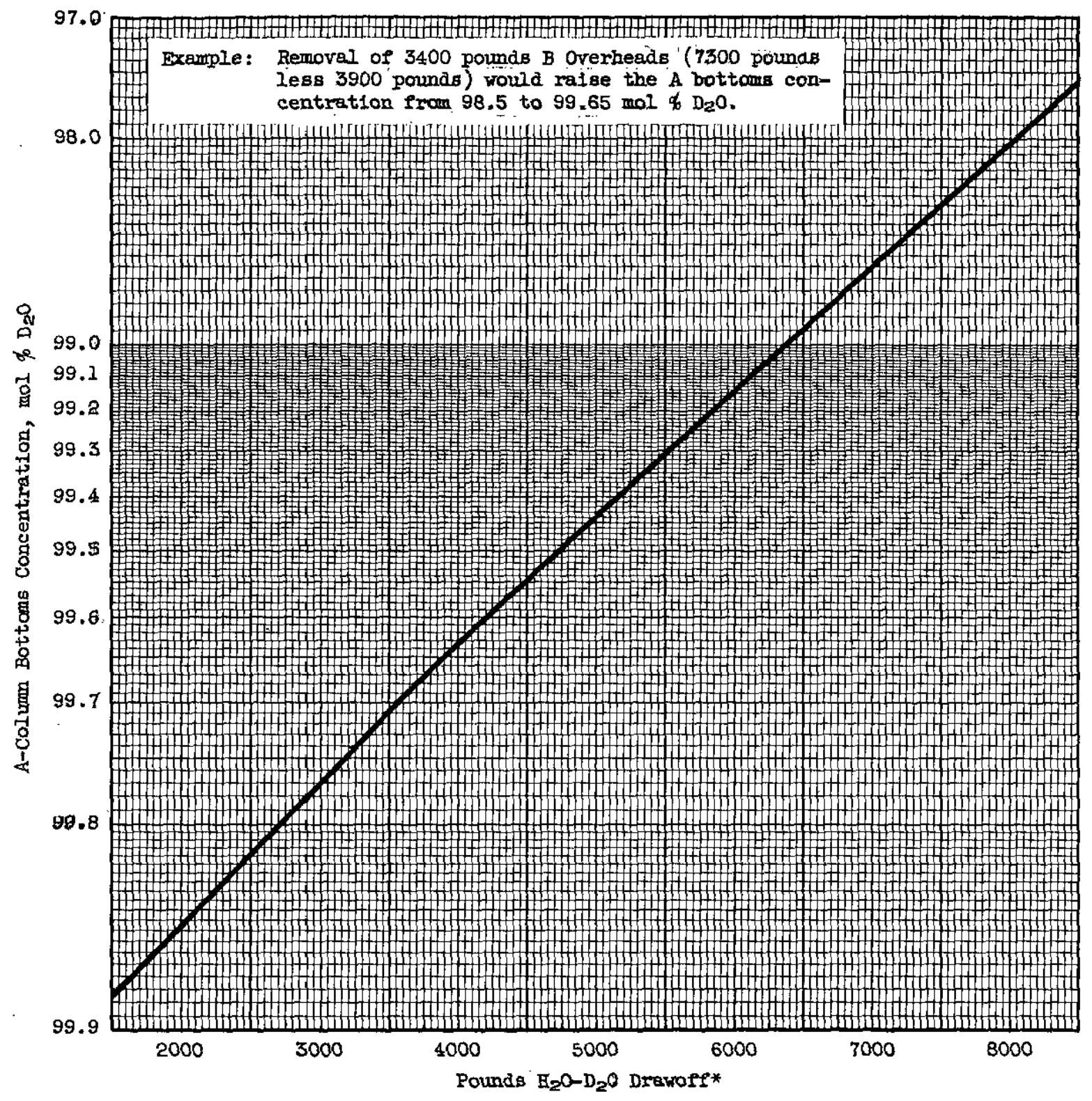

Figure 32. Plot for Determining Amount of Drawoff to Change A Bottoms Concentration*

* Based on a reference $\mathrm{B}$ overheads concentration of 94.3 mol of $\mathrm{D}_{2} \mathrm{O}$. 


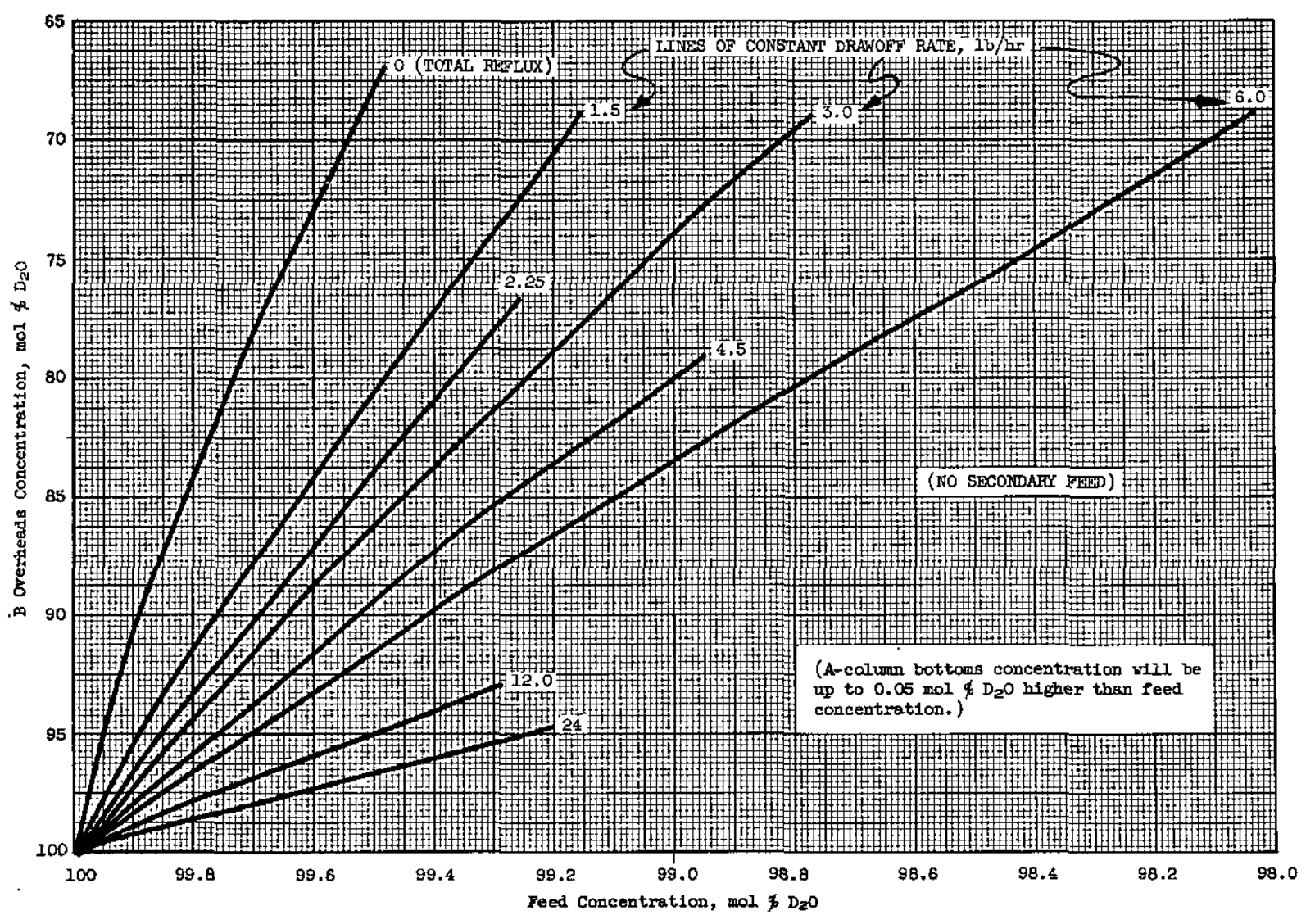

Figure 33. Feed Concentration and B Overheads Concentration at Various Drawoff Rates 


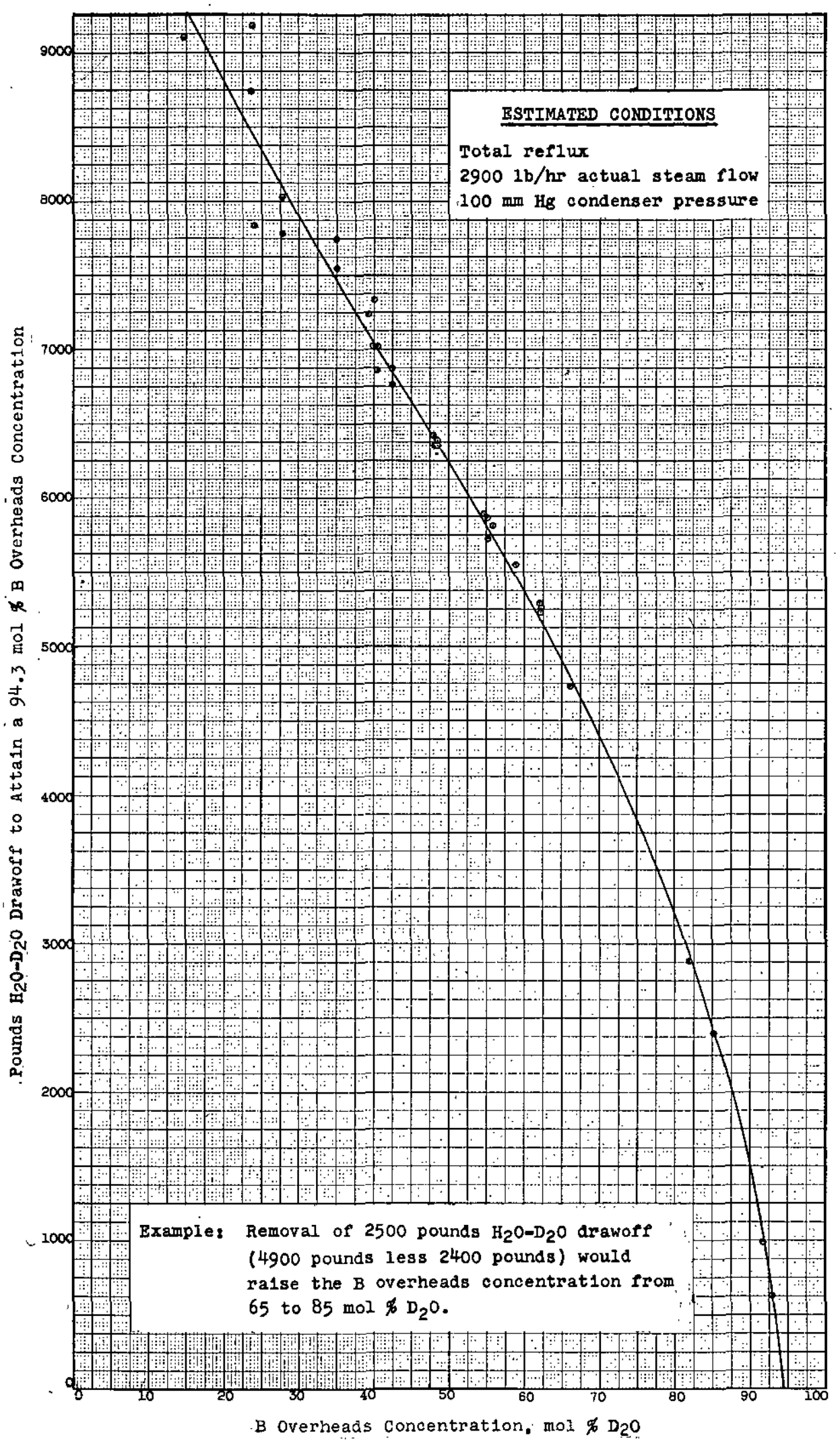

Figure 34. Plot for Determining Amount of Drawoff to Change $B$ Overheads Concentration 
$y_{D}=$ moil $\$ \mathrm{H}_{2} \mathrm{O}$ in Overheads of Colurm Chosen for Secondary Feed

$\mathrm{v}_{\mathrm{B}}=\mathrm{mol} \phi_{\mathrm{H}_{2} \mathrm{O}}$ in Bottoms of Column Chosen for Secondary Feed $\mathrm{y}_{\mathrm{F}}=\mathrm{mol} \phi_{\mathrm{H}_{2} \mathrm{O}}$ in Secondary Feed

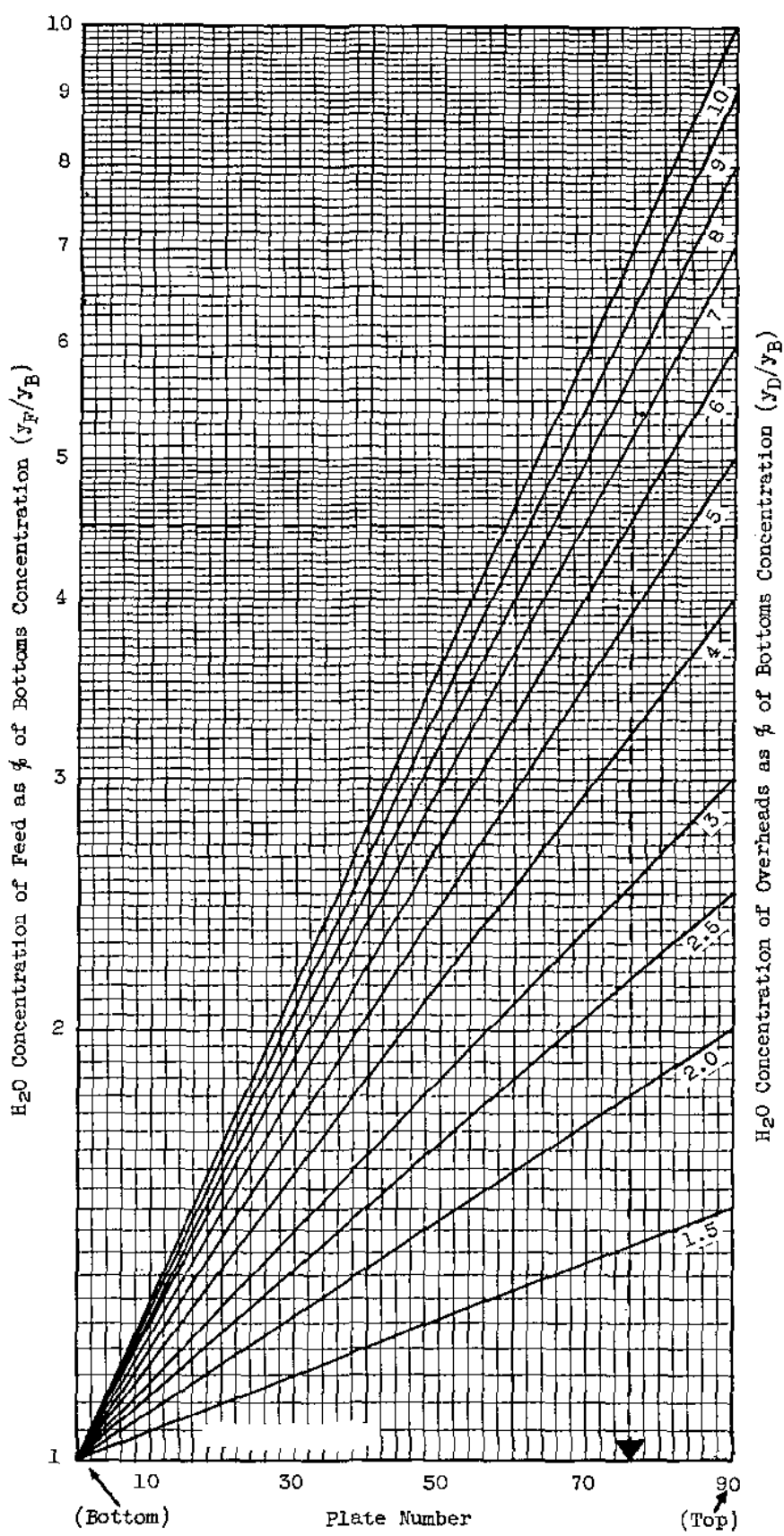

Figure 35. Plot for Locating Secondary Feed Point 